\title{
Mesoscale Circulations and Organized Convection in African Easterly Waves
}

\author{
LORENZO TOMASSINI \\ Met Office, Exeter, United Kingdom
}

(Manuscript received 29 June 2018, in final form 9 October 2018)

\begin{abstract}
Global convection-permitting model simulations and remote sensing observations are used to investigate the interaction between organized convection, both moist and dry, and the atmospheric circulation in the case of an African easterly wave (AEW). The wave disturbance is associated with a quadrupole structure of divergence, with two convergence centers slightly ahead of the trough. Moisture transport from southeast of the trough to the area in front and lower midtropospheric moisture convergence precondition and organize convection. The main inflow into the squall-line cluster is from behind. The moisture-abundant inflow collides at the low level with monsoon air with high moist static energy and establishes a frontal line of updrafts at the leading edge of the propagating mesoscale convective system. A mantle of moisture surrounds the convective core. A potential vorticity budget analysis reveals that convective latent heating is driving the evolution of the wave but not in a quasi-steady way. The wave propagation includes a succession of convective bursts and subsequent dynamic adjustment processes. Dry convection associated with the Saharan air layer (SAL) and SAL intrusions into the wave trough together with vorticity advection can play a role in intensifying AEWs dynamically as they move from the West African coast across the Atlantic Ocean. Our analysis demonstrates that the synoptic-scale wave and convection are interlinked through mesoscale circulations on a continuum of scales. This implies that the relation between organized convection and the atmospheric circulation is intrinsically dynamic, which poses a particular challenge to subgrid convection parameterizations in numerical models.
\end{abstract}

\section{Introduction}

Dunn's (1940) paper on isallobaric waves is one of the outstanding contributions to tropical meteorology. Isallobaric waves in the tropical Atlantic are now known as African easterly waves (AEWs). Herbert Riehl extended Dunn's analysis when working at the Institute of Tropical Meteorology at Rio Piedras in Costa Rica (Lewis et al. 2012). Riehl recognized that areas of convergence and divergence as well as diabatic heating and evaporative cooling are central features of the waves (Riehl 1945). Riehl's influential book on tropical meteorology (Riehl 1954) summarized his insights into the interaction between moist convection and the atmospheric circulation in the tropics at that time.

Riehl's book is cited in Charney (1963), and tropical depressions like those resulting from easterly waves were considered to be a model for the tropical circulation as a whole. Charney and Eliassen (1964) proposed a theory of the interaction between moist convection and

Corresponding author: Lorenzo Tomassini, lorenzo.tomassini@ metoffice.gov.uk the circulation in tropical depressions and termed the mechanism convective instability of the second kind (CISK). CISK emphasizes the role of low-level moisture convergence in triggering and governing convection, an aspect that was also observed and described by Riehl in his work on easterly waves. Riehl explains the depth of the moist layer by convergence and divergence, and relates convection and thunderstorm formation to the depth of the moist layer (Riehl 1945).

Emanuel et al. (1994) vividly criticized Charney and Eliassen's conceptual view and, citing Arakawa and Schubert (1974) among others, argued that moist convection requires instability and should be regarded as a process of adjustment. Emanuel et al. (1994) refer to the observation that in tropical cyclones convection acts to adjust the atmospheric state toward a moist adiabatic profile. The impact of Emanuel et al. (1994) was so profound that during the 1990s and 2000s, and probably still to date, most weather and climate models employ convection parameterizations that are based on the quasi-equilibrium view of Emanuel et al. (1994) and implicitly consider convection as an adjustment process that consumes convective available potential energy 
(CAPE) in reaction to larger-scale instabilities. Emanuel et al. (1994) suggested that convective adjustment actually dampens synoptic-scale tropical disturbances and called the process "moist convective damping."

It is not accidental that Emanuel et al. (1994) cite the Marshall Islands and tropical western Pacific sounding data as observational evidence for their quasi-equilibrium hypothesis, whereas the starting point of the discussion in Charney and Eliassen (1964) are cold-core tropical disturbances like easterly waves. Over the tropical western Pacific, the atmospheric profile is indeed maintained close to moist adiabatic by oceanic convection (Neelin and Held 1987; Xu and Emanuel 1989; Holloway and Neelin 2007). In conditionally unstable atmospheres over land, however, lower- to midtropospheric moisture dynamics governs the formation of convection in many situations. Also, in subsidence regions over the ocean, moisture can play an important role in organizing shallow-convective structures (Bretherton and Blossey 2017).

In the case of AEWs, it has been clearly demonstrated that moist convection can sustain and intensify the disturbances (Berry and Thorncroft 2005, 2012; Tomassini et al. 2017). Moisture convergence related to the wave circulation in the lower midtroposphere plays an important role in triggering and organizing convection. Convection parameterizations based on moisture convergence closures tend to perform better than CAPE closure schemes over tropical Atlantic land areas (Skinner and Diffenbaugh 2013; Siongco et al. 2017). However, this does not mean that purely diagnostic moisture convergence closure schemes adequately represent mesoscale convective systems and their interaction with AEWs. The recent success of convection-permitting simulations suggests that ultimately a prognostic element in the representation of the interaction between convection and the atmospheric circulation is necessary. As there is no scale separation between convection and the larger scales, it is suggested in the present study that organized moist convection is linked to the larger scale through mesoscale circulations, which play an important role in mediating upscale and downscale effects. In fact, similar findings were described already in early observational studies, such as those that emerged from the Global Atmospheric Research Program Atlantic Tropical Experiment (GATE; Burpee 1975; Reed et al. 1977; Thompson et al. 1979; Houze and Betts 1981; Karyampudi and Carlson 1988), or Riehl's work at the Institute of Tropical Meteorology.

A more comprehensive and fundamental picture of the interaction of moist convection and the atmospheric circulation is only just starting to emerge (Smith 1997; Raymond et al. 2015; Schulz and Stevens 2018), and this study aims to contribute to advancing our understanding in this respect. Recently convection-permitting simulations, as used in this study, have become possible over large domains. They provide the opportunity to examine convection in great detail under a variety of real-world conditions, which will lead to a deeper understanding of the richness of convection-circulation coupling. This paper extends the AEW case analysis of Tomassini et al. (2017) using a global convection-permitting simulation. After introducing the model setup (section 2), the focus is placed on the structure of the mesoscale circulations related to AEWs, and the mechanisms that sustain associated mesoscale convective systems (section 3). In addition, a potential vorticity (PV) budget analysis is presented in order to understand the cycling of potential vorticity in the AEW system and the relative importance of latent heat release (section 4). Finally, the role of the Saharan air layer (SAL) and SAL intrusions into the wave trough are investigated in detail from a PV perspective (section 5), a process that is important in the development of easterly waves into hurricanes over the tropical Atlantic. A discussion section, section 6, concludes the paper.

\section{Global convection-permitting AEW simulation}

The case of a strong AEW described in Tomassini et al. (2017) is analyzed in further detail using global convection-permitting simulations with the Met Office Unified Model Global Atmosphere 7.0 (GA7; Walters et al. 2017) at 5-km (N2560) resolution. The simulations were initialized with analyses from the European Centre for Medium-Range Weather Forecasts (ECMWF). The wave travels from its genesis region over the Sudanian mountains to the coast of West Africa and across the Atlantic Ocean from 7 to 15 July 2010. Three forecast start dates will be considered: 0000 UTC 7 July, 0000 UTC 11 July, and 1800 UTC 12 July. The rationale for the chosen initial times will be explained in the subsequent discussion. In the following the location of the wave trough is identified subjectively based on the 700-hPa meridional wind anomaly.

Sensitivity experiments have been performed with the model in order to identify a reasonable convectionpermitting configuration. In the end a CAPE closure time scale of $1.5 \mathrm{~h}$ was chosen for the midlevel convection parameterization. This allows the convection parameterization to remove some of the instability while a large part of the vertical motion remains resolved, with precipitation generated mainly by the model's largescale microphysics scheme. As in Tomassini et al. (2017), the deep and shallow convection parameterizations were turned off. The shallow convection parameterization did not have a substantial impact on the simulation 
over land. The deep convection scheme mainly produces erroneous rainfall around noon every day as a direct response to the maximum solar incoming radiation and shows little sensitivity to the wave disturbance. Hovmöller plots of precipitation and potential vorticity at $700 \mathrm{hPa}$ are shown in Fig. 1 and compared to the respective quantities from the Tropical Rainfall Measuring Mission (TRMM) 3B42 V7 dataset (Huffman et al. 2007) and ECMWF operational analysis.

Based on the model output fields, satellite brightness temperature and reflectivity were simulated for the SEVIRI instrument on the Meteorological Satellite (Meteosat) Second Generation (MSG). As an example Fig. 2 shows the satellite scenes for the visible $0.8-\mu \mathrm{m}$ reflectivity and the infrared $10.8-\mu \mathrm{m}$ wavelength brightness temperature (left column), and the corresponding simulated imagery (right column) at 1500 UTC 10 July. The start time of the model simulation is 0000 UTC $7 \mathrm{July}$; that is, the satellite-simulated images are based on a forecast with $87 \mathrm{~h}$ lead time. The approximate wave trough as diagnosed from the model simulation is indicated by a red dashed line in the right panels.

Even at a lead time of almost 4 days, the model is able to reproduce most of the individual convective features that can be identified in the satellite image. It is obvious that the cloud structure related to the mesoscale convective system (MCS) around the wave trough shows a somewhat too organized and too circular structure, characteristics often encountered with convectionpermitting models. In reality there seem to be two main centers of updrafts ahead of the trough, whereas in the model there is one larger convective area ahead of the trough and a larger stratiform cloud region around and behind the trough. The structure of this MCS will be analyzed in more detail in section 3. The model misses some low clouds mainly over the Guinea Coast, an aspect that is not central for the present study. As the satellite images reveal, around the wave trough there are mainly high convective clouds surrounded by cloudfree areas.

As the situation around 1800 UTC 10 July will be analyzed in more detail in section 3, Fig. 3 shows precipitation at this time of the day in a region around the wave trough. The TRMM precipitation product (Huffman et al. 2007, top-left panel) is usually interpreted as a 3-h mean. Since it is based on satellite remote sensing of high clouds, it might underestimate areas of light rain as well as smaller areas of precipitation. Qualitatively however it agrees well with the satellite images of Fig. 2, and generally the TRMM 3B42 V7 dataset was evaluated favorably against ground-based observations over West Africa at the temporal and spatial resolution considered here (Guilloteau et al. 2016; Pfeifroth and Trentmann 2016).
The hourly mean precipitation related to the MCS around the wave trough in the model simulation (topright panel) also broadly agrees with the cloud characteristics shown in Fig. 2. As demonstrated below in section 3 , the rainfall ahead of the trough stems from strong convective updrafts, whereas the precipitation at and behind the trough is of stratiform nature. The model shows more areas of precipitation, and more lighter rainfall, than TRMM, a feature that is not so obvious from the cloud field alone (Fig. 2).

For comparison, total precipitation from ECMWF analysis forecasts are shown in Fig. 3 as well (bottom row), with forecast start times of 1200 UTC 9 July (bottom-left panel) and 0000 UTC 10 July (bottom-right panel). The ECMWF Integrated Forecast System (IFS), which is used both in the forecasts and in the analysis, includes a convection parameterization. Although the forecast with an initialization time of 0000 UTC 10 July produces a reasonable convective system ahead of the wave trough, it is obvious from the forecast initialized on 9 July that the model struggles to sustain propagating MCSs.

\section{Mesoscale circulations and sustained organized convection}

Although mesoscale convective systems over the Sahel have been studied quite extensively before, it is still not very well understood what exactly sustains them over periods of $24 \mathrm{~h}$ and more, notably through the nighttime during which the boundary layer is stable near the surface. What are the mechanisms that sustain MCSs associated with AEWs, and what is the role of the wave circulation in maintaining the MCSs? To better understand the relation between mesoscale circulations, the organized convection ahead of the wave trough, and the AEW, we restrict the discussion to one particular time, namely, 1800 UTC 10 July. This is after local sunset, and a focus of the investigation will be the mechanisms that sustain the MCS in the evening and during the night.

The wave manifests itself in the wind at $700 \mathrm{hPa}$ as a large bend in the African easterly jet (AEJ; streamlines Fig. 4a). This results in a quadrupole structure in the divergence field with two distinct centers of convergence north and south, slightly ahead of the trough. This quadrupole structure of convergence and divergence in AEWs was described in Riehl (1945), and it is consistent with the general pattern of quasigeostrophic jet-streak circulations (e.g., Uccellini and Kocin 1987). The black dashed line in the plot indicates the location of the wave trough, and the cross sections along the green and the blue lines will be shown below. The point where the 
(a) TRMM precipitation
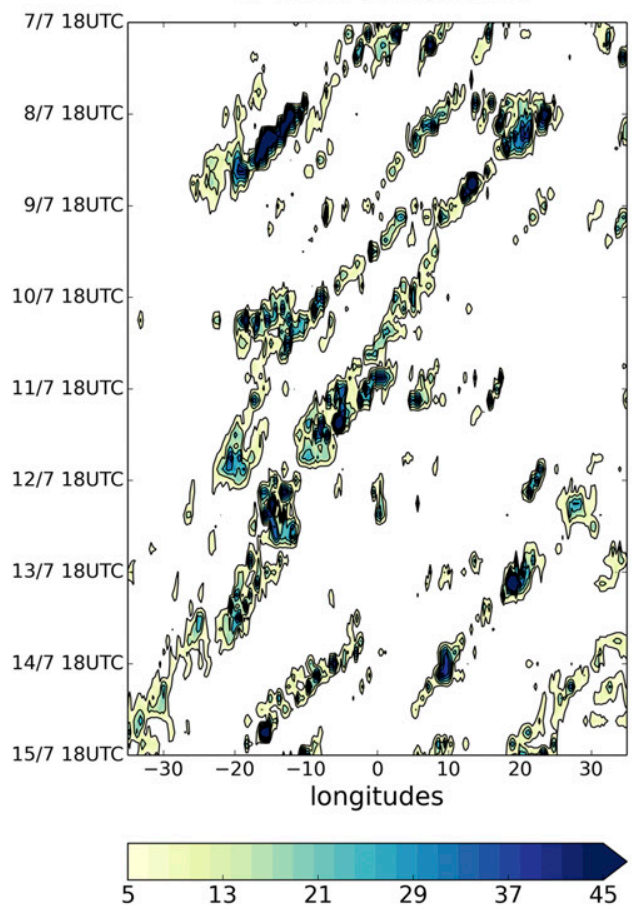

[mm/day] (b) Model precipitation
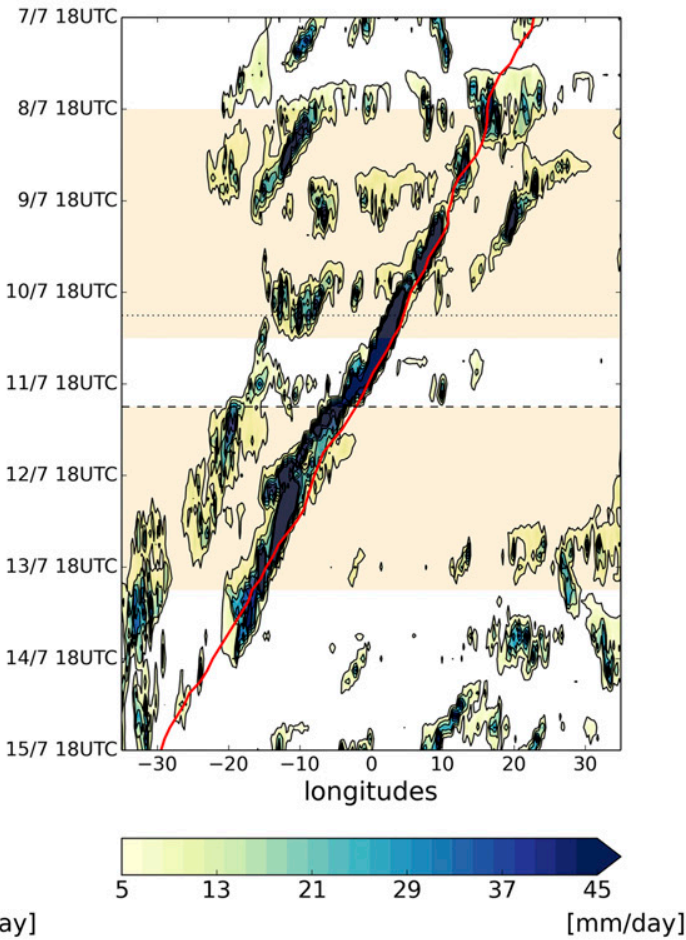

(d) Potential vorticity $700 \mathrm{hPa}$
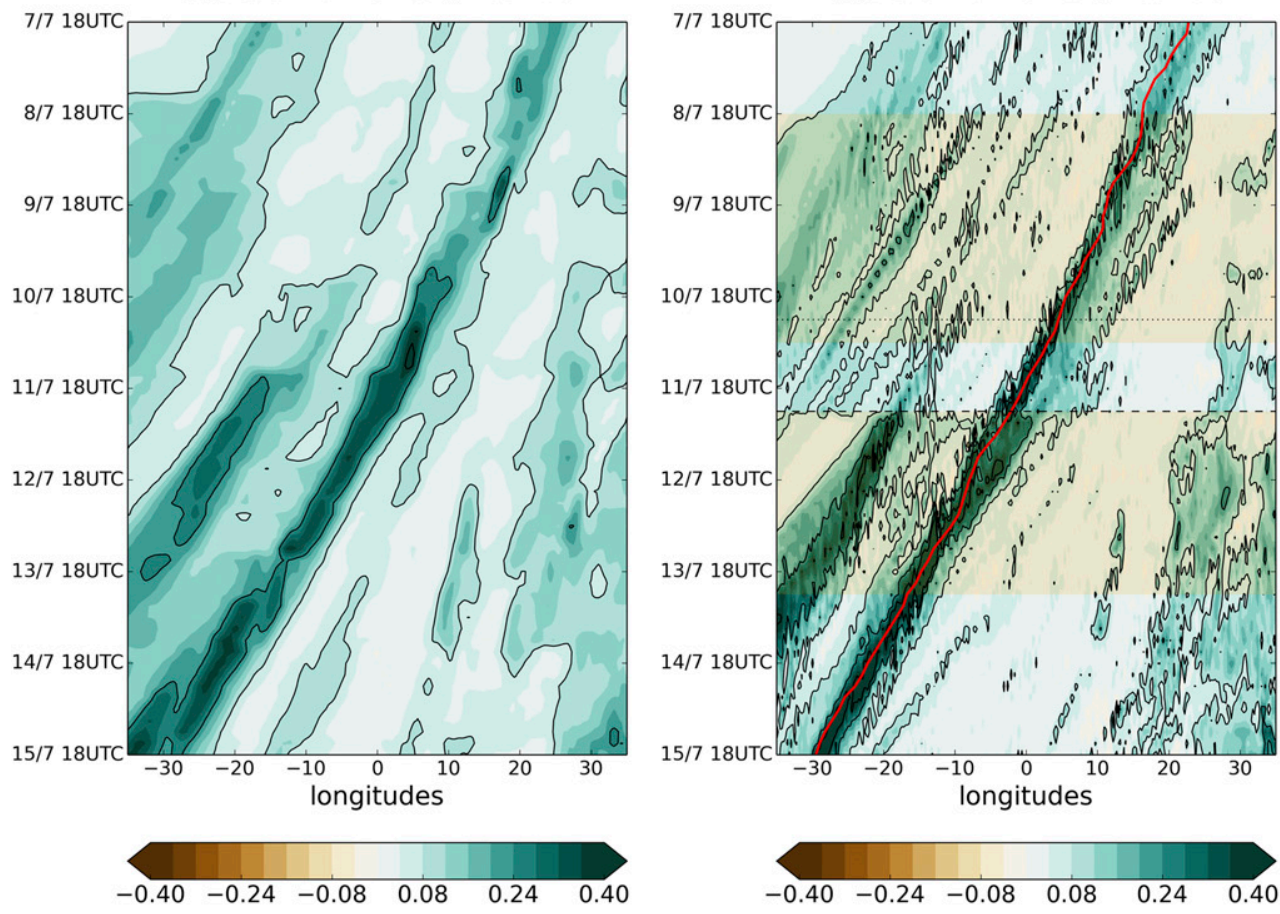

[PVU]

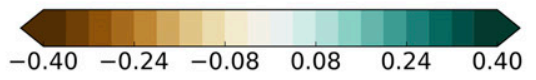

[PVU]

FIG. 1. Hovmöller plot of (a) TRMM precipitation, (b) model precipitation, (c) PV in ECMWF analysis at $700 \mathrm{hPa}$, and (d) PV at $700 \mathrm{hPa}$ in the model simulation for the considered AEW case. The data were averaged over the latitudes $10^{\circ}-20^{\circ} \mathrm{N}$. The yellow shaded areas in (b) and (d) define the two periods of wave growth that are investigated in the PV budget analysis in section 4. The red lines indicate the approximate location of the wave trough in the model run. Horizontal dotted lines indicate forecast initialization times; horizontal dashed lines indicate from which time on the data of a new forecast are used. 


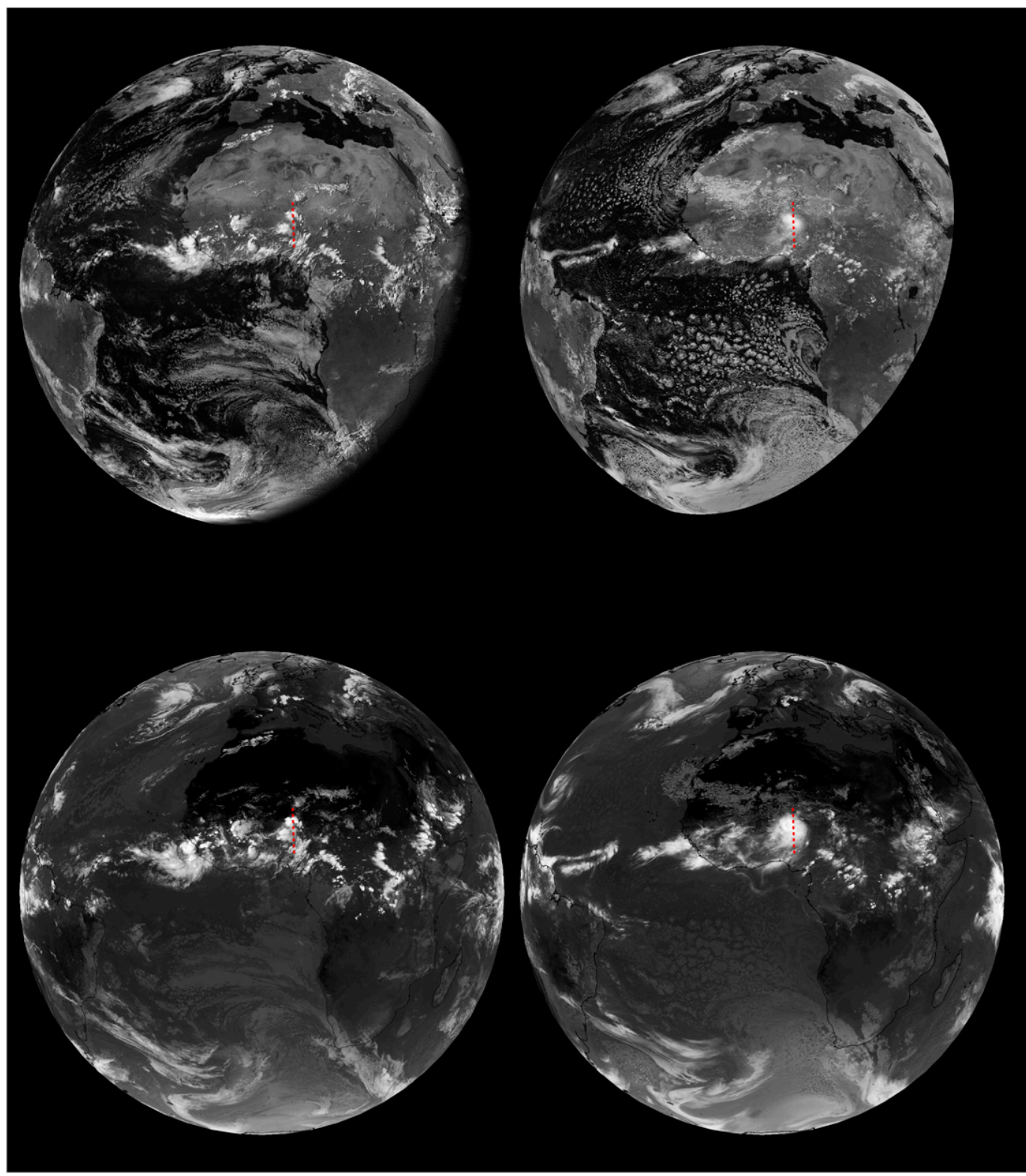

FIG. 2. (top left) Reflectivity from the SEVIRI instrument on the MSG at $0.8-\mu \mathrm{m}$ (visible) at 1500 UTC $10 \mathrm{Jul}$. (top right) The same quantity simulated based on the model run. (bottom left) Brightness temperature from the SEVIRI instrument on the MSG at $10.8-\mu \mathrm{m}$ at 1500 UTC $10 \mathrm{Jul}$. (bottom right) The same quantity simulated based on the model run. The approximate trough location as diagnosed from the model simulation is indicated by a red dashed line in the images.

green and blue lines cross is about the center of the MCS (Fig. 3b). It roughly coincides with the area of strongest convergence at $700 \mathrm{hPa}$ ahead of the trough.

The upward vertical velocities corresponding to the MCS are organized in a distinct curved line, constituting a propagating front (Fig. 4b). Judging from the satellite scenes (Fig. 2), the model likely overestimates the degree of convective organization, and in many instances there seems to be two or more convective cores ahead of the wave trough in reality. Nevertheless, qualitatively the model seems to reproduce the structure of the organized convective system well, and the narrow convective front is in agreement with the more detailed satellite observations of a squall-line case described in Lafore et al. (2017). There are regions of descent in the middle troposphere, both ahead and behind the front, broader than the narrow updrafts. The second precipitation feature behind the wave trough seen in Fig. $3 b$ does not correspond 

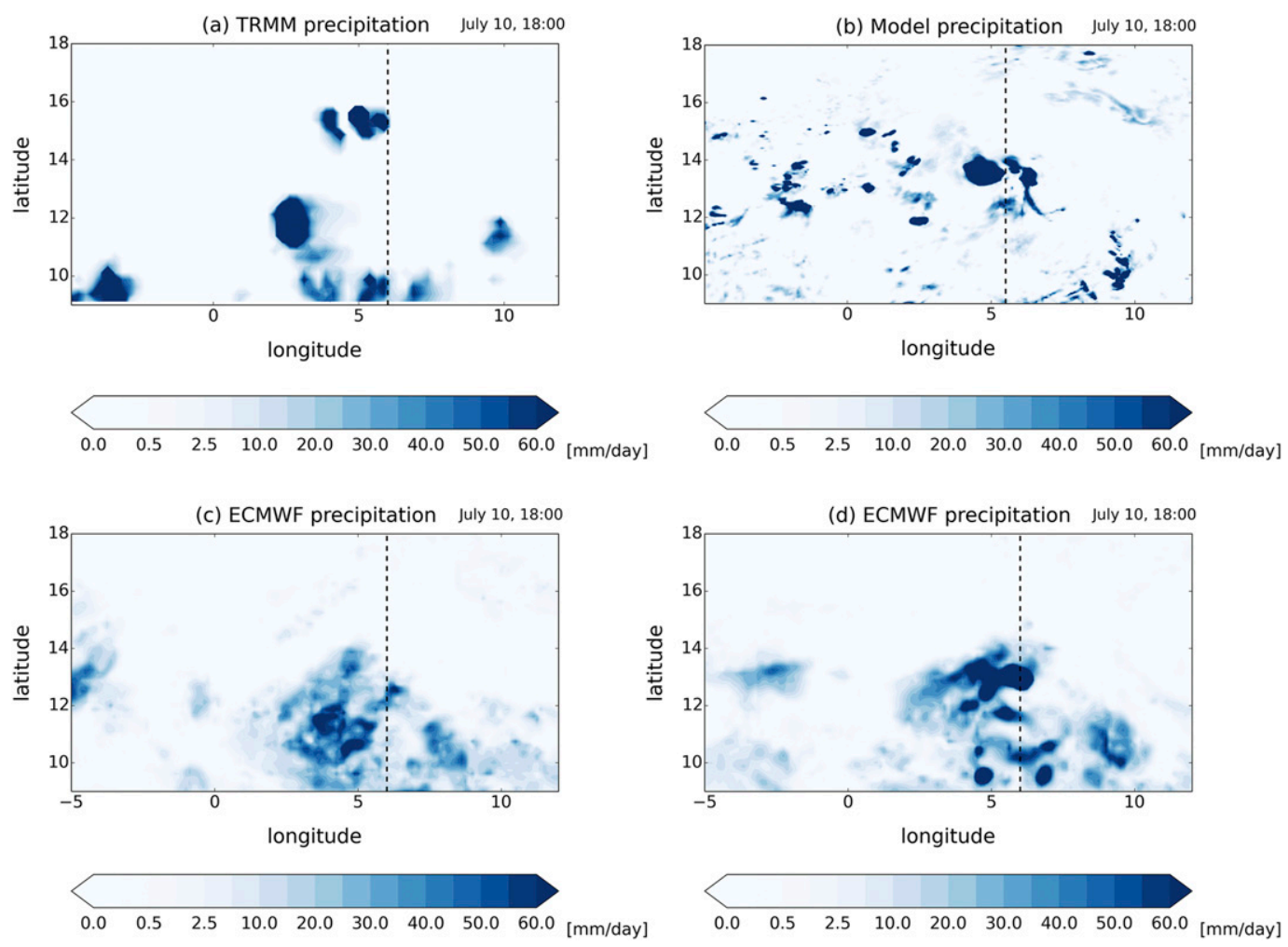

FIG. 3. (a) TRMM precipitation at 1800 UTC 10 July; the dashed line indicates the trough at $6^{\circ} \mathrm{E}$ as diagnosed from ECMWF analysis. (b) Corresponding model precipitation showing the trough at $5.5^{\circ} \mathrm{E}$ as diagnosed from the model (dashed line); model forecast initial time is 0000 UTC 7 Jul. (c) ECMWF operational analysis precipitation forecast with start time of $1200 \mathrm{UTC} 9 \mathrm{Jul}$; trough indicated at $6^{\circ} \mathrm{E}$ (dashed line). (d) ECMWF operational analysis precipitation forecast with start time of 0000 UTC $10 \mathrm{Jul}$. For both models the rainfall rates have been regridded onto the $0.25^{\circ} \mathrm{TRMM}$ grid.

to strong upward vertical velocities and is thus of stratiform nature.

The horizontal component of relative vorticity at $700 \mathrm{hPa}$ is mainly positive and is centered around the wave trough (Fig. 4c) as to be expected. It looks broadly similar to the potential vorticity (Fig. 4d), but there are differences. The positive potential vorticity signature extends farther ahead of the trough to the location where convection occurs, suggesting that convection plays a role in generating potential vorticity, as discussed in Tomassini et al. (2017) and in the PV budget analysis in section 4 .

To better understand the structure of the mesoscale circulations around the MCS ahead of the wave trough, cross sections of the different wind components along the green line (Fig. 4) are presented in Fig. 5. The left panels show the absolute wind components, the right panels the anomaly relative to a 10-day temporal mean. The meridional wind component is dominated by the anomaly created by the wave. It is southerly in the midtroposphere behind the trough, and northerly in front of the trough. At the center of the MCS the meridional wind is substantially slowed down. At low levels, below about $1500 \mathrm{~m}$, there is southerly flow, which turns abruptly northerly behind the front of the MCS as part of the mesoscale circulation of the convective system. The flow ahead of the squall line is in fact southwesterly (Figs. 5c.d) and feeds into the MCS. Between about 1500- and 2000-m height, the flow is northwesterly, and above that the wind is still dominated by the African easterly jet, although the wave together with the MCS induce a strong westerly anomaly (Fig. 5d), particularly ahead of the MCS.

This means that at low levels, below about $1500 \mathrm{~m}$, warm and moist air feeds into the front of the MCS. However, as will be seen later (Fig. 8), the main moisture anomaly created by the wave circulation, with moisture drawn in from behind and southeast of the trough, is located above this low-level, 1500-m-deep monsoon layer. Although the collision of the warm and moist monsoon-layer air with the MCS front is a main factor in the sustainment of the MCS, it is the midtropospheric moist anomaly that preconditions and governs the development of organized convection ahead 

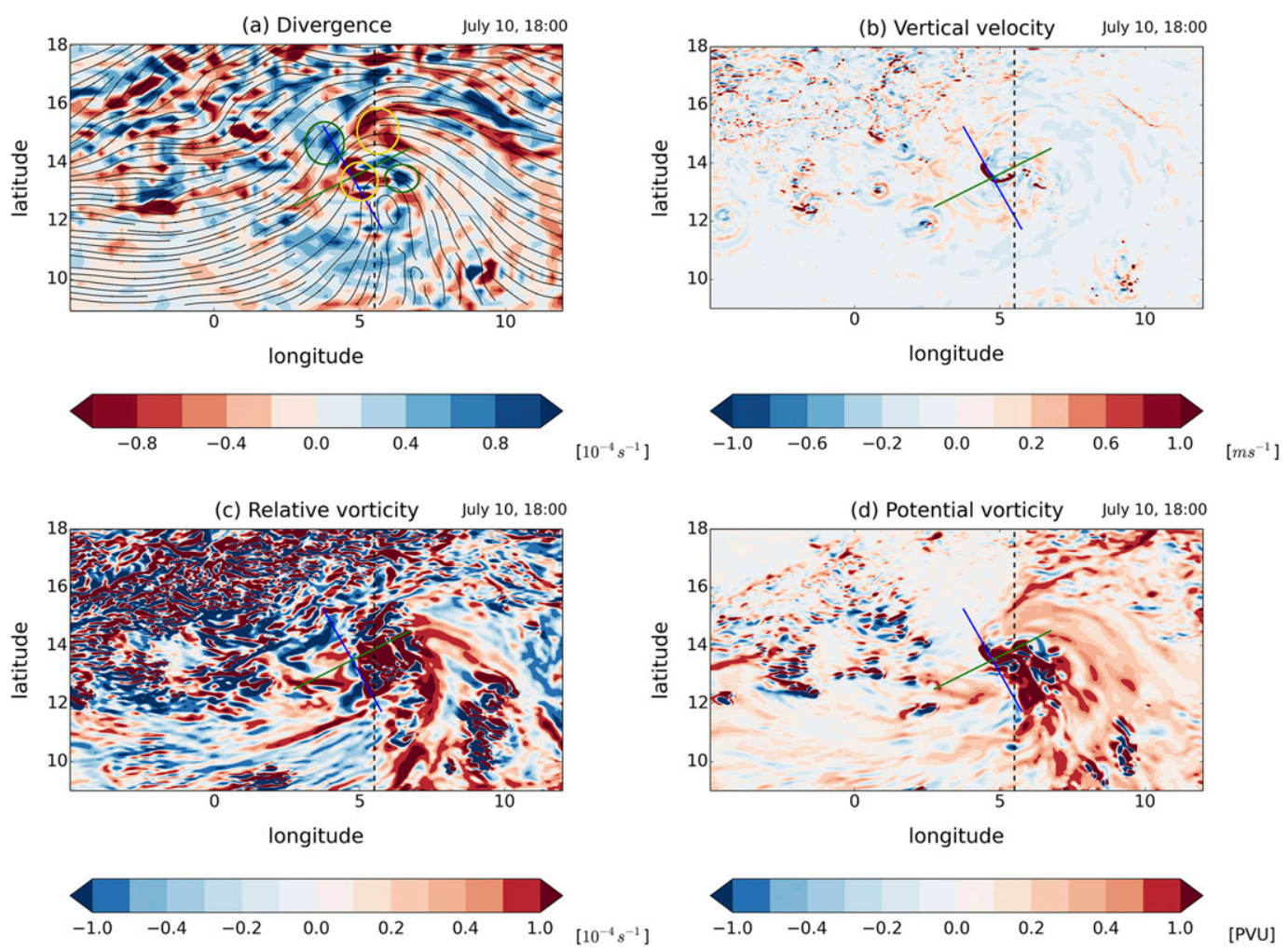

FIG. 4. (a) Horizontal divergence of the wind field at 1800 UTC $10 \mathrm{Jul}$ at $2800-\mathrm{m}$ height, corresponding to about $700 \mathrm{hPa}$; the streamlines of the wind field are indicated by black lines; yellow and green circles highlight regions of convergence and divergence, respectively. Analogous plots for (b) vertical velocity, (c) relative vorticity, and (d) potential vorticity. The blue and green lines define the locations of cross sections that are used in the subsequent analysis; the black dashed line defines the location of the wave trough.

of the trough. The dominant inflow region into the MCS is from the northeast, which supports the propagation of the system westward. There are thus two sources of moisture and high moist static energy air that sustain the MCS: at low levels air from the southwest; and at midtropospheric heights, moist air is drawn in by the wave trough that originates southeast of the MCS and curls around the wave center, flowing into the MCS from the northeast and to some degree northwest.

The vertical velocities show a strong area of ascent at the front of the MCS (Figs. 5e,f), consistent with Fig. 4. Broader areas of descent can be identified mainly behind the front. This feature is somewhat different from the description of squall clusters in Houze and Betts (1981), where descending motions are observed only at lower levels, but similar to cases observed by Jenkins et al. (2010), in which subsiding air reaches to levels of $8 \mathrm{~km}$ or more in the stratiform region. The line of strongly ascending air is slightly slanted backward, indicating that the updrafts are initiated at around 15002000-m height. This implies that immediately behind the ascending front, there is upward motion at upper levels and downward motion below around $5000 \mathrm{~m}$, in agreement with Houze and Betts (1981). With respect to the shear generated by the AEJ, the slope of the updrafts is upshear below the wind speed maximum of the AEJ and downshear above, whereas in the classical squall-line model the updrafts are considered to slope upshear (Seitter and Kuo 1983).

Accordingly, a region of divergence between 3000 and $5000 \mathrm{~m}$ can be identified immediately behind the front of the MCS (Fig. 6a). At low levels the main region of convergence is slightly ahead of the midtropospheric area of convergence and upward vertical motion, consistent with the idea that moisture convergence induced by the mesoscale circulation creates the necessary conditional instability to initiate convection (Tomassini et al. 2017). The cross sections of divergence and vertical velocity along the blue line of Fig. 4 (south to north) reveal further interesting aspects of the structure of the MCS (Figs. 4b and 4c). The narrow front of upward vertical velocities does not initiate at the same height everywhere. In the south, where low-level moisture is more abundant, the upward vertical motion is rooted 

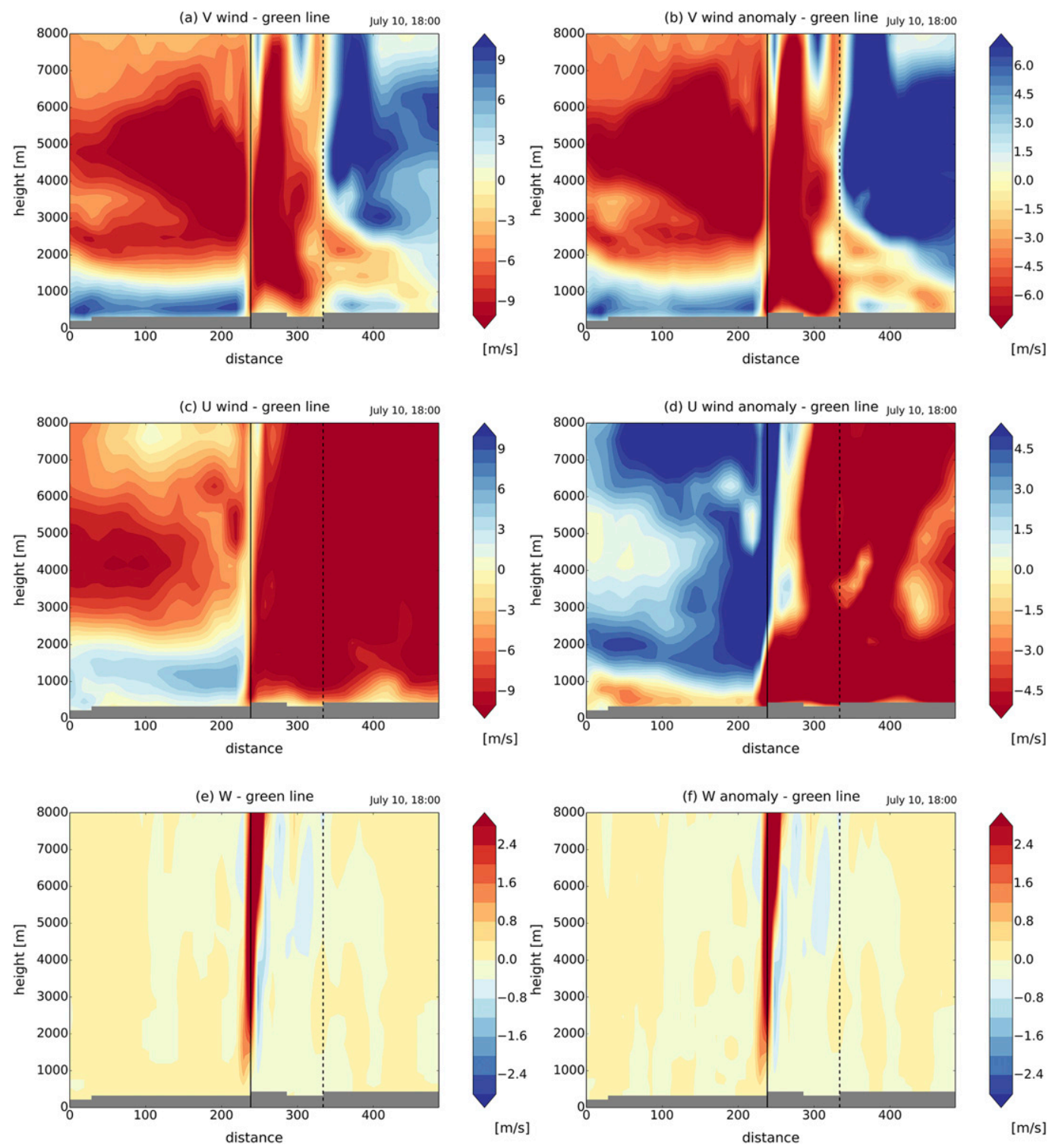

FIG. 5. Cross sections along the green line (see Fig. 4) from SW to NE for (a) meridional wind, (c) zonal wind, and (e) vertical velocity; and (b),(d),(f) corresponding anomalies at 1800 UTC 10 Jul. The black line indicates the point where the green line and the blue line of Fig. 4 cross, i.e., the location of the center of the MCS; the dashed line is the trough location.

deeper in the lower troposphere, whereas farther north convection is initiated and sustained more by the midlevel moisture anomalies and triggered in the midtroposphere. The area of convergence is broader and encompasses also the region of lower-tropospheric descent immediately behind the MCS front.

It is instructive to examine the boundary layer structure around the MCS and the wave trough. In the model different boundary layer types are diagnosed during the simulation. Over most of the land area in question, the model identifies a stable boundary layer at 1800 UTC
(Fig. 7b), including the area ahead of the MCS front. In the inner part of the MCS, a cloud layer, either stratocumulus or cumulus, over a stable boundary layer is mainly signalized. A stable boundary layer means a negative surface buoyancy flux and a stable stratification near the surface. This implies that the air near the surface is not buoyant by itself. The convective instability feeding the MCS is created by conditional instability caused by the moisture anomaly and uplift of air caused by mesoscale circulations. There is a distinct region ahead of the MCS with a substantially elevated turbulent 

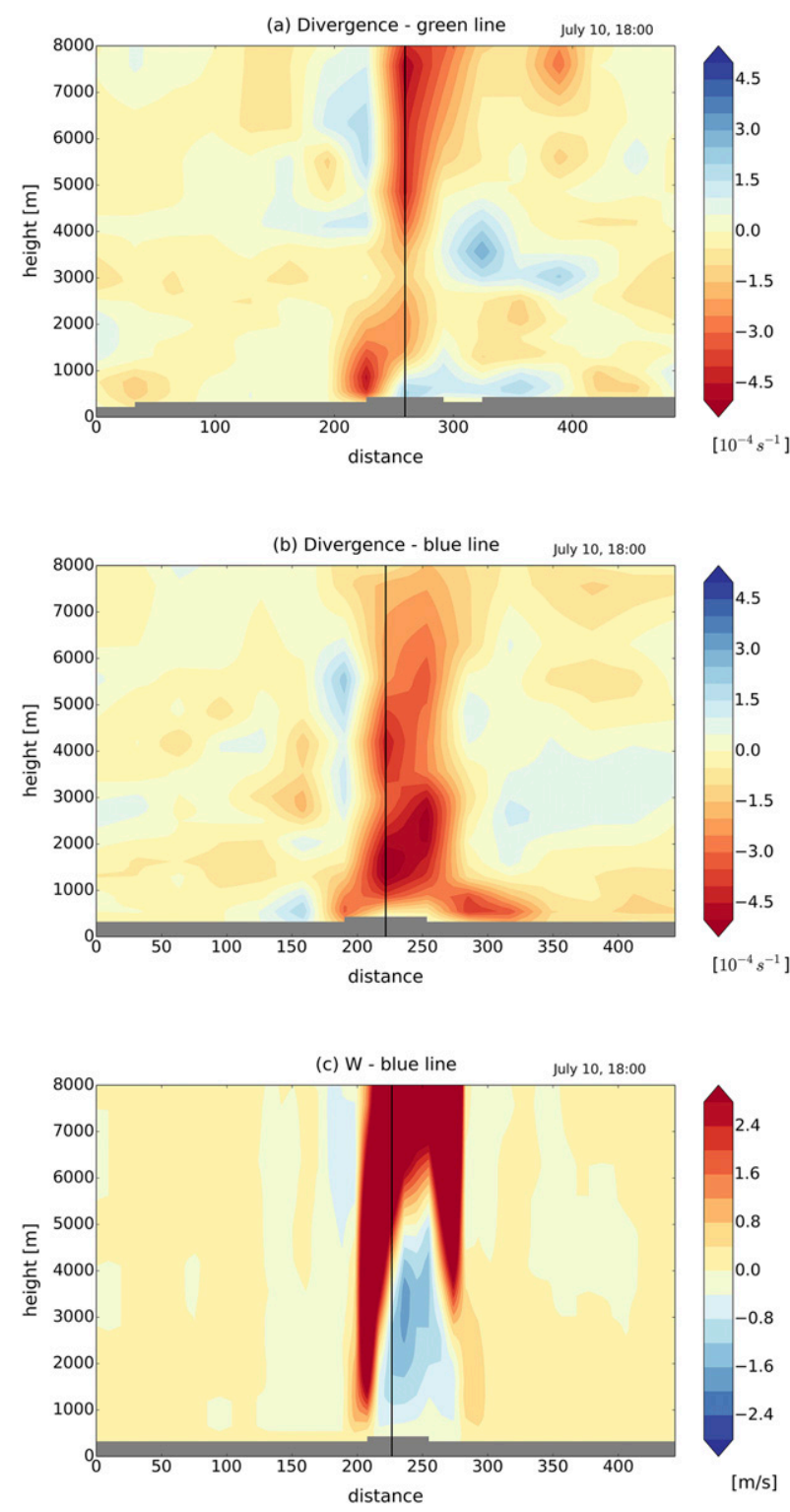

FIG. 6. (a) Cross section along the green line (see Fig. 4) from SW to NE for horizontal wind divergence at 1800 UTC 10 Jul. (b) Cross section for the same quantity and the same time, but along the blue line (see Fig. 4) from SE to NW. (c) Cross section along the blue line from SW to NE for vertical velocity. The black line indicates the point where the green line and the blue line of Fig. 4 cross, i.e., the location of the center of the MCS (not the trough location).

mixing height - that is, a deep layer of air with a bulk Richardson number smaller than a critical value-which means that shear production dominates buoyant consumption of turbulence in the lower part of the atmosphere ahead of the MCS.

The turbulent mixing height is overlaid as a black line in the cross-sectional plot of the specific humidity anomaly along the green line (Fig. 8a). The positive moisture signature in the lower midtroposphere between 1000 and 3000-m heights ahead of the MCS preconditions the atmosphere and allows convection to ultimately break through the lower midtroposphere. At the location of the upward motion, a distinct shell of moisture shields the convective core from the environment as described also in idealized simulations by Becker et al. (2018). Behind the convective core, the impact of the anvil and the stratiform rain region can be identified. At lower levels behind the MCS front, where downward motion dominates, the mesoscale circulation removes moisture. The temperature anomaly shows the cooling by advection, together with cooling from evaporation of precipitation, at lower levels at and behind the MCS (Fig. 8b). Ahead of the MCS front, the negative temperature anomaly coincides with the region of the main positive moisture anomaly in the lower midtroposphere. Only in the boundary layer a warm anomaly occurs that is caused by the enhanced southwesterly flow. At upper levels the effect of the latent heating at and behind the main region of ascent is apparent. In terms of clouds, the imprint of the MCS is most distinctly seen in the positive cloud ice anomaly that extends from the region of the convective updrafts to the stratiform region behind (Fig. 8c).

The patterns of equivalent and saturation equivalent potential temperature clearly bear out the conditional instability ahead of the MCS created mainly by the moisture anomaly, and the near-neutral state at the location of the most intense updrafts and vertical mixing (Fig. 8d). The conditional instability reaches into the midtroposphere and is not confined to the boundary layer in the traditional sense. However, ahead of the MCS the turbulent mixing height attains up to $3000 \mathrm{~m}$, indicating that turbulent mixing caused by wind shear is intense and contributes to the development of organized convection where air with high moist static energy is mixed throughout the lower midtroposphere. The described moisture dynamics and the associated circulations sustain the mesoscale convective system. Cloudtop cooling at the top of the MCS anvil cloud is small, on the order of $0.25 \mathrm{~K} \mathrm{~h}^{-1}$ (not shown), as the cloud tops reach as high as $12 \mathrm{~km}$ and consist of cloud ice, and hence can be excluded as a major mechanism for maintaining the MCS. Behind the center of the MCS, the stratification is stable and the imprint of the upperlevel heating from stratiform cloud and rainfall formation can be detected.

The two sketches in Fig. 9 summarize the most important features of the MCS and their relation to the wave, one depicting a view from above (Fig. 9a) and the other illustrating a longitude-height cross section (Fig. 9b). Key features of the synoptic-scale wave that organizes 
(a) Turbulent mixing height july 10, 18:00

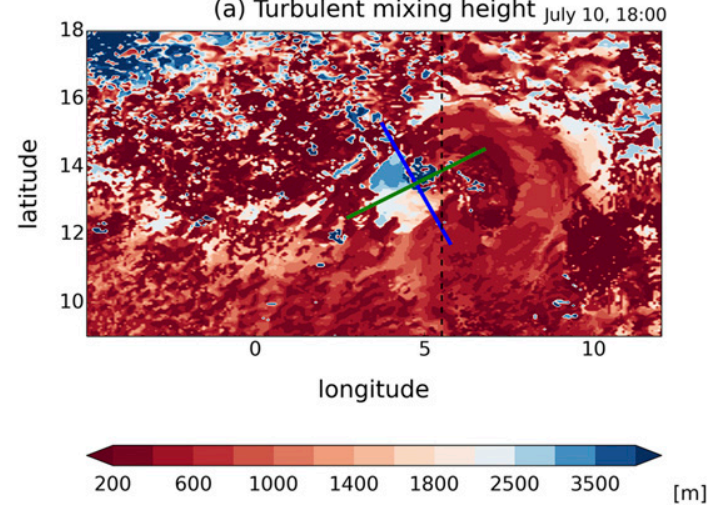

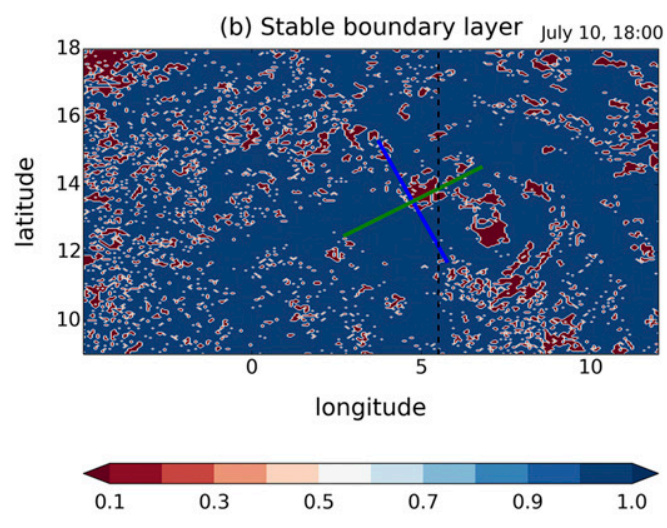

FIG. 7. (a) Turbulent mixing height in the model simulation at 1800 UTC 10 Jul. (b) Boundary layer-type indicator in the model simulation for a stable boundary layer for the same date and time. A value of one means the model diagnoses a stable boundary layer. For stable conditions, the turbulent mixing height is defined to be the level where the bulk Richardson number is larger than a critical value. The dashed black line again indicates the trough location of the AEW.

convection include a quadrupole structure of divergenceconvergence, moisture transport at midlevels above $3 \mathrm{~km}$ from the region southeast of the trough to the area ahead of the trough, and patches of strong shear (Fig. 9a). The MCS core ahead of the trough consists of a narrow, curved front of strong updrafts that comes with its own mesoscale circulation. This front collides with the low-level, high-moist-static-energy monsoon flow and is fed and pushed by the northeasterly, moisture-bearing inflow. Around the convective core, a distinct shell of moisture forms (Fig. 9b). There are downdrafts close to the front, both ahead and to the rear, and a broader region of descending air in the lower and midtroposphere behind. The stratiform anvil cloud consists mainly of cloud ice.

\section{Potential vorticity budget analysis of the wave evolution}

In the previous section, the detailed structure of the mesoscale circulations that determine and maintain the MCS, and the relationship of these circulations to the synoptic-scale AEW, were discussed. In the present section, the upscale effect of convection on the wave dynamics is investigated by analyzing the PV budget along the development of the wave, and the contribution of diabatic terms to the wave growth.

The approach taken for the analysis is sketched in Fig. 10. The PV budget is computed for boxes that follow the track of the AEW as indicated in the figure. The geometrical boxes extend both in the horizontal and in the vertical directions. Haynes and McIntyre (1987) showed that neither diabatic nor frictional forces result in a net transport of PV across isentropic surfaces. However, here a moving geometrical area will be considered along the track of which the wave grows and total PV increases. We thus aim to investigate processes through which the PV changes along the propagation of the wave. As discussed in detail in Tory et al. (2012), when MCSs are present, secondary circulations develop and advection away or toward sources and sinks of PV can be significant. In this case different terms in the PV budget may be opposed to each other and the residual may be small. Nevertheless, it is instructive to calculate the different terms in the budget in order to understand the balances that are at work. For instance, Hoerling (1992) has previously pointed out that because part of the atmospheric flow is related to diabatic heating, advective tendencies of $\mathrm{PV}$ are linked to tendencies caused by diabatic sources and are thus not independent.

Tory et al. (2012) discuss different forms of the PV budget equations. Which formulation to adopt depends in part on what question is to be answered, and also on the nature of the data that are available for the computation of the budget. For the global convectionpermitting simulation, the spatial resolution is rather high, but only 3-hourly output is available. Potential vorticity substance (PVS) defined as

$$
\mathrm{PVS}=\rho P=\boldsymbol{\eta} \cdot \nabla \theta,
$$

which represents the amount of PV per unit volume of physical space and behaves in a manner similar to a chemical tracer in a fluid (Haynes and McIntyre 1987; Tory et al. 2012). Here $P$ is PV, $\rho$ is density, $\boldsymbol{\eta}=\nabla \times \mathbf{u}+f \mathbf{k}$ absolute vorticity, and $\theta$ is potential temperature. The following decomposition of the PVS tendency equation is used subsequently [see Eq. (6b) in Tory et al. 2012]: 

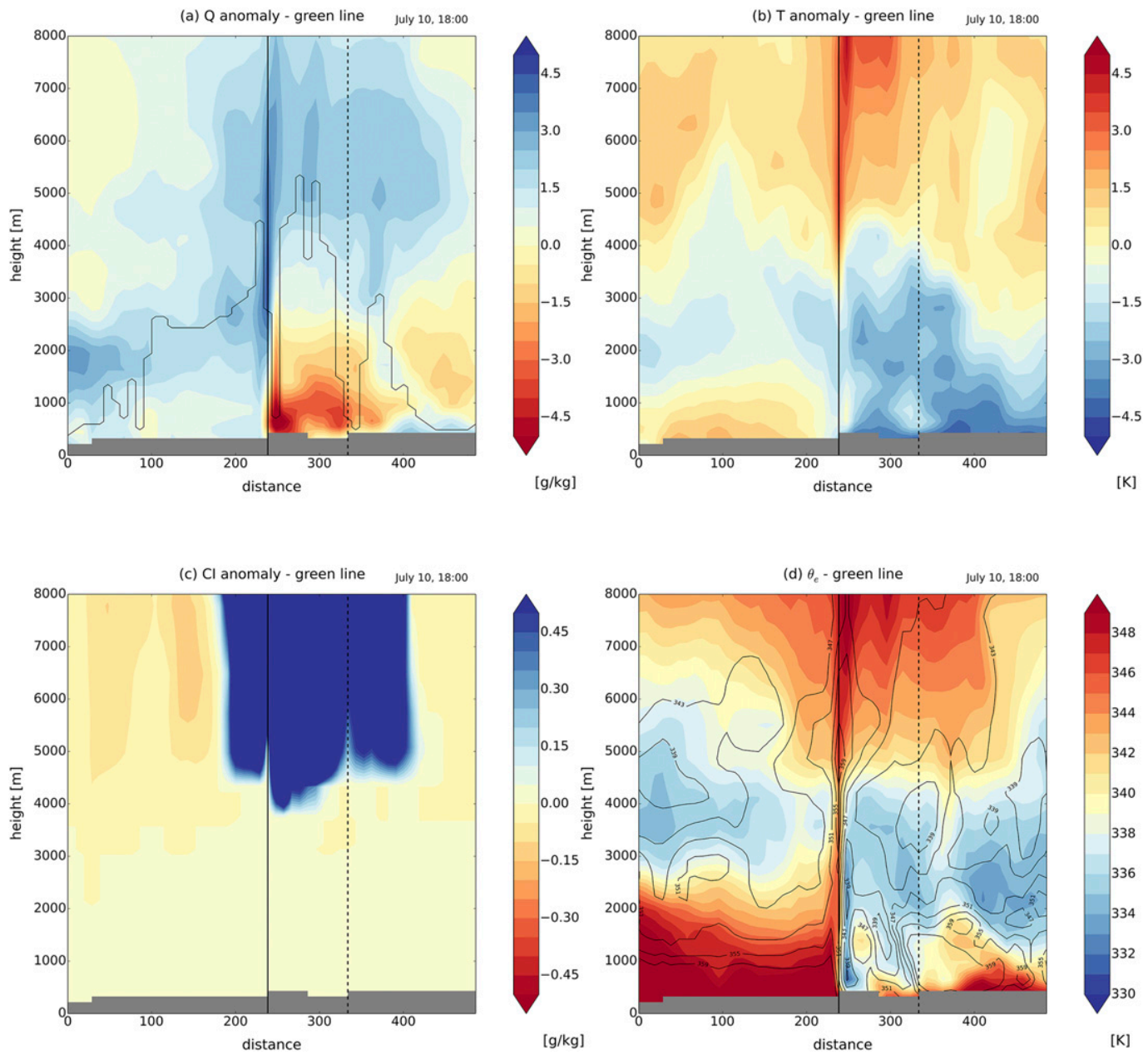

FIG. 8. Cross sections along the green line (see Fig. 4) from SW to NE at 1800 UTC 10 Jul for (a) specific humidity anomaly, (b) temperature anomaly, (c) cloud ice anomaly, and (d) equivalent potential temperature. The contour in the specific humidity anomaly plot shows the turbulent mixing height; the contours in (d) indicate saturation equivalent potential temperature values. The vertical black lines in the different panels mark the point where the green line and the blue line of Fig. 4 cross, i.e., the location of the center of the MCS; the dashed line is the trough location.

$$
\begin{aligned}
& \frac{\partial(\rho P)}{\partial t}=-\operatorname{div}(\mathbf{u} \cdot \rho \cdot P)+\underbrace{\boldsymbol{\eta} \cdot \nabla S_{\theta}+\overbrace{\nabla \theta \cdot \nabla \times \mathbf{S}_{\mathbf{u}}}^{\text {Friction }}}_{\text {Sources }} \\
& =-[\underbrace{\mathbf{u}_{h} \cdot \nabla \rho P}_{\text {Horizontal advection }}+\underbrace{\left(\operatorname{divu}_{h}\right) \cdot \rho P}_{\text {Horizontal divergence }} \\
& +\underbrace{w \frac{\partial \rho P}{\partial z}+\frac{\partial w}{\partial z} \rho P}_{\text {Vertical flux }}]+ \text { Sources }
\end{aligned}
$$

where the three-dimensional wind field is decomposed as $\mathbf{u}=\left(\mathbf{u}_{h}, w\right)$.

The main source term related to subgrid potential temperature tendencies is further decomposed into vertical and horizontal tendencies from latent heating, and tendencies from radiation and subgrid turbulent mixing:

$$
\begin{aligned}
\boldsymbol{\eta} \cdot \nabla S_{\theta}= & \underbrace{\boldsymbol{\eta}^{1} \frac{\partial S_{\theta}^{\text {latent }}}{\partial x}+\boldsymbol{\eta}^{2} \frac{\partial S_{\theta}^{\text {latent }}}{\partial y}}_{\text {Horizontal part latent }}+\underbrace{\boldsymbol{\eta}^{3} \frac{\partial S_{\theta}^{\text {latent }}}{\partial z}}_{\text {Vertical part latent }} \\
& +\boldsymbol{\eta} \cdot \nabla S_{\theta}^{\text {bl+rad }} .
\end{aligned}
$$

All terms are integrated over a box that extends from $2.5^{\circ}$ west to $2^{\circ}$ east of the trough, and from 650 to $11800 \mathrm{~m}$ above ground in the vertical. The temporal evolution of PVS - that is, the left-hand side of Eq. (2) - is computed as a difference of the integrated PVS between two points in time, whereas all the other terms are computed from instantaneous 3-hourly values and are assumed 


\section{a}

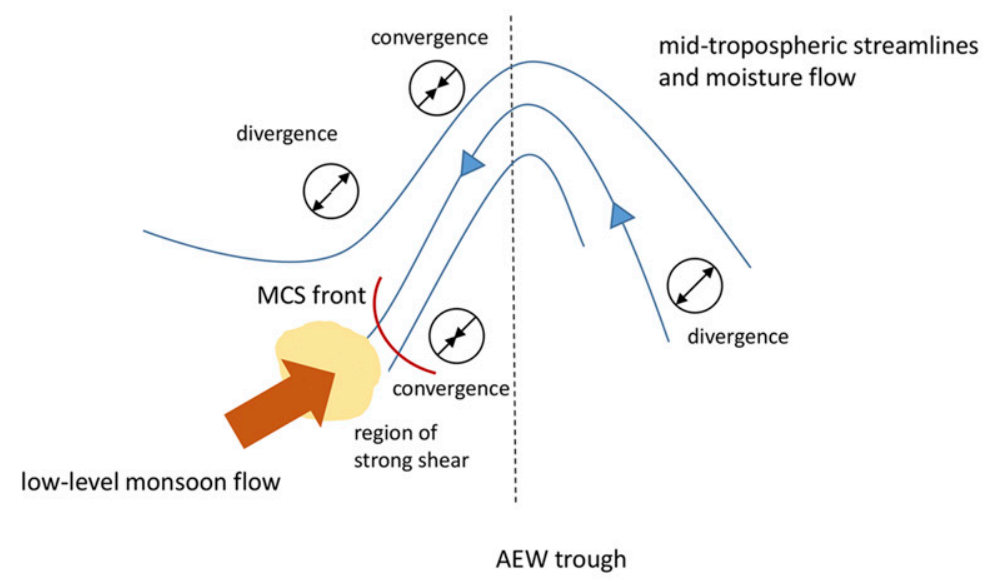

b

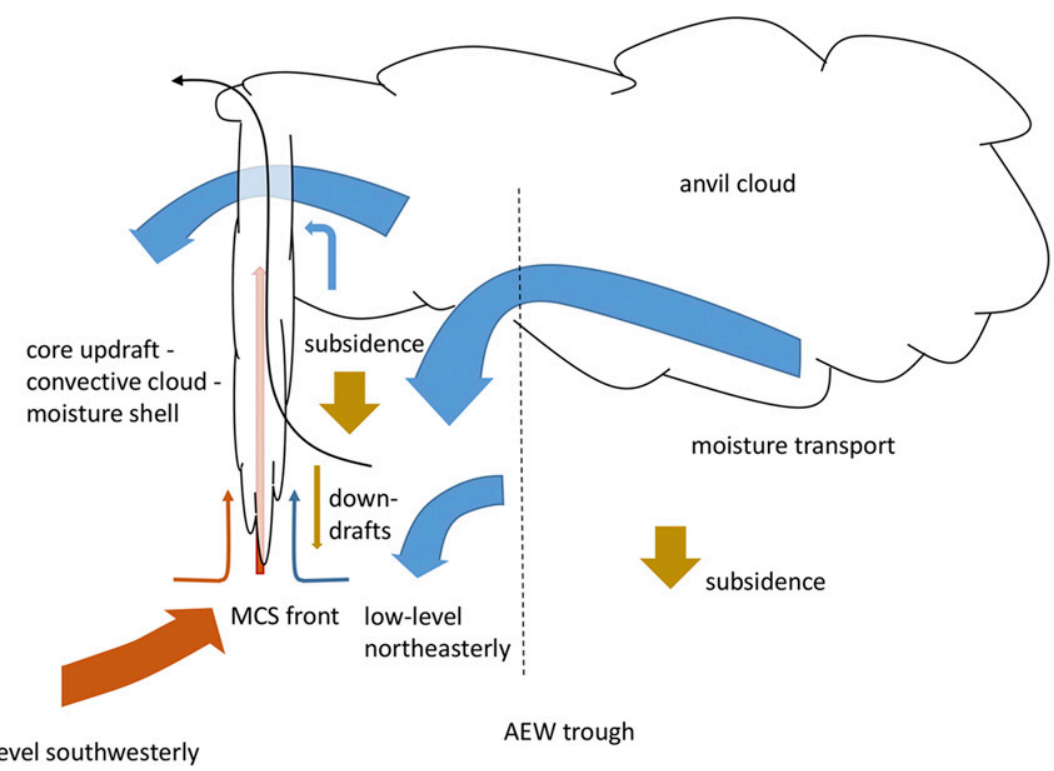

FIG. 9. Conceptual sketches summarizing the characteristics of the squall-line cluster and its interaction with the AEW: (a) view from above onto the longitude-latitude plane and (b) a schematic depiction of a longitude-height cross section. See main text for more details.

to be constant over the respective 3-h period. To account for the fact that the trough is moving, a mean zonal wind of $4 \mathrm{~m} \mathrm{~s}^{-1}$ is subtracted from the zonal wind, as done in the example of a moving convective burst in Tory et al. (2012). All the terms are normalized such that the total volume of the boxes is equal to one. Various sensitivity calculations were performed with varying mean wind speeds and height-dependent mean wind profiles, but qualitatively the results were robust. Also, all fields were smoothed with a uniform Fourier filter with a box size of four values before the budget was calculated in order to remove gridscale noise. Again, this has an impact on the exact magnitude of the numbers but not on the qualitative nature of the result.
Two phases of the wave evolution are considered as indicated by yellow shading in Fig. 1. The first phase represents the main period of the initial wave growth, and the second phase encompasses a strengthening of the wave at a stage when the wave is already fully developed. The forecast with the initial time of 0000 UTC 7 July is used during the first phase; the forecast with the start time of 0000 UTC 11 July is used for the second phase.

The blue lines in the top panels of Fig. 11 show the development of the integrated PVS over the two time periods. In the first phase, the total budget - that is, the sum of the right-hand side of Eq. (2) (green lines in the 


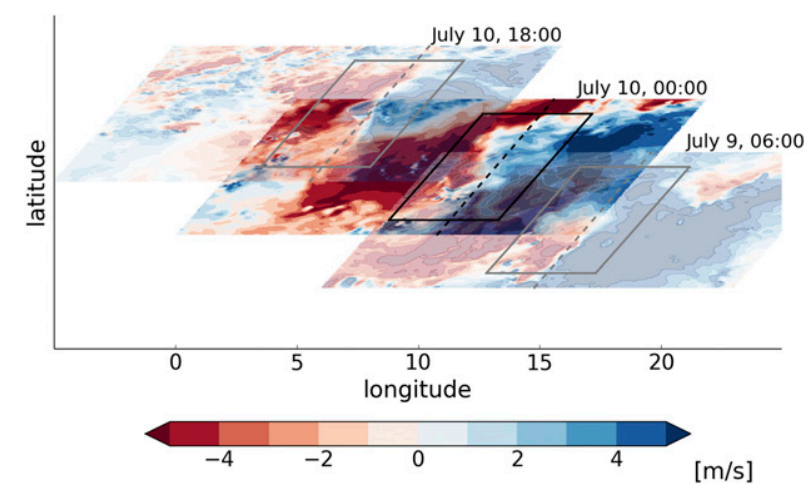

FIG. 10. Illustration of the areas over which the PV budget is calculated. Boxes around the moving trough extend both in the horizontal and in the vertical directions. In the horizontal the areas cover the latitudes $10^{\circ}-17^{\circ} \mathrm{N}$, and the region $2.5^{\circ}$ west of the trough to $2^{\circ}$ east of the trough. The vertical extent of the boxes (not indicated here) reaches from 660 - to $11800-\mathrm{m}$ heights. The color shading in the sketch corresponds to meridional wind anomalies in the model simulation.

top panels of Fig. 11) - is quite close to the change in PVS (red lines in the top panels) - that is, the estimate of the left-hand side of Eq. (2). During the second phase, there is a certain offset between the two, but the overall variability of the evolution is better explained.

As pointed out in Tory et al. (2012), some of the individual terms of the budget are up to one order of magnitude larger than the total change in PVS (middle panels in Fig. 11). The two main cancellations in the budget decomposition defined by Eqs. (3) and (4) are 1) between the horizontal advection and the horizontal divergence, and 2) between the vertical and the horizontal latent heating sources. The sum of the horizontal advection and the horizontal divergence represents the horizontal flux of PVS across the lateral boundaries of the box. The compensating mechanism between the vertical and horizontal terms of the latent heating source [see Eq. (4)] is related to what Tory et al. (2012) call "tilting like" process in diabatic heating regions [see also the appendix of Tory et al. (2006)]. At the edges of diabatic heating regions, isentropes are tilted by horizontal gradients in the diabatic potential temperature tendencies.

Given these two balancing pairs of terms, it is instructive to consider the total source from latent heating (i.e., the sum of the vertical and horizontal PVS sources) and the total "dynamic evolution and adjustment" contribution (i.e., the sum of the horizontal advection and divergence) (bottom panels of Fig. 11). A qualitative difference is evident between the first phase and the second phase. During the first phase, wave growth is mainly driven through the PVS source generated by latent heating. During the second phase, when the MCS is fully developed, the dynamic evolution and adjustment term is more in line with the wave evolution. One could argue that there is a time lag between the PVS contribution from latent heating and the wave evolution on the order of $12 \mathrm{~h}$. The potential presence of such a phase lag has already been suggested in Davies (1979). It is unlikely that such a long time scale is related to the time scale of removal of convective instability by a single cloud or cloud ensemble. Instead, it is more plausible that such a lag is linked to the transfer of PVS from small convective scales to larger synoptic scales mediated through mesoscale circulations. The relationship between latent heating and dynamic evolution and adjustment is not as close as one might expect (Tory et al. 2012). Nevertheless, the variations in magnitude of the respective individual components (middle panels in Fig. 11) follow each other quite closely.

The friction term and the PVS contributions from the boundary layer and radiation parameterizations are generally rather minor, but they can occasionally attain nonnegligible values. In both terms a signature of the diurnal cycle can be detected to some degree, with larger values in the afternoon and early evening. The vertical extent of the boxes over which the budget is calculated was chosen such that the vertical flux in or out of the box is relatively small.

To gain a qualitative understanding of the vertical structure of some of the terms involved in the PVS budget, Fig. 12 shows mean profiles of potential vorticity, relative vorticity, vertical velocity, total temperature tendency from latent heating, and horizontal wind divergence at a particular time late in the first phase, namely, 0000 UTC 11 July. The dotted lines indicate the bottom and top boundaries of the box used for the PVS budget calculation. In order for the vertical structure of latent heating to act as a PVS source, the vertical gradient needs to be positive. At the same time, there has to be positive relative vorticity present. This situation is mainly given at lower midtropospheric levels of around $3000-5000 \mathrm{~m}$. From this region PVS will be advected upward by the vertical velocity. The strongest wind convergence occurs in the lower troposphere, aloft mainly divergence dominates. Therefore, PVS is generated and concentrated at lower levels, transported upward, and pushed out of the column either laterally or to some degree through the top of the column. At lower levels lateral advection out of the box is strongest, compensating the convergence to some degree as discussed above, but PVS accumulation dominates. The low-level inflow and convergence, and upper-layer outflow and divergence of PVS can thus also be observed in 

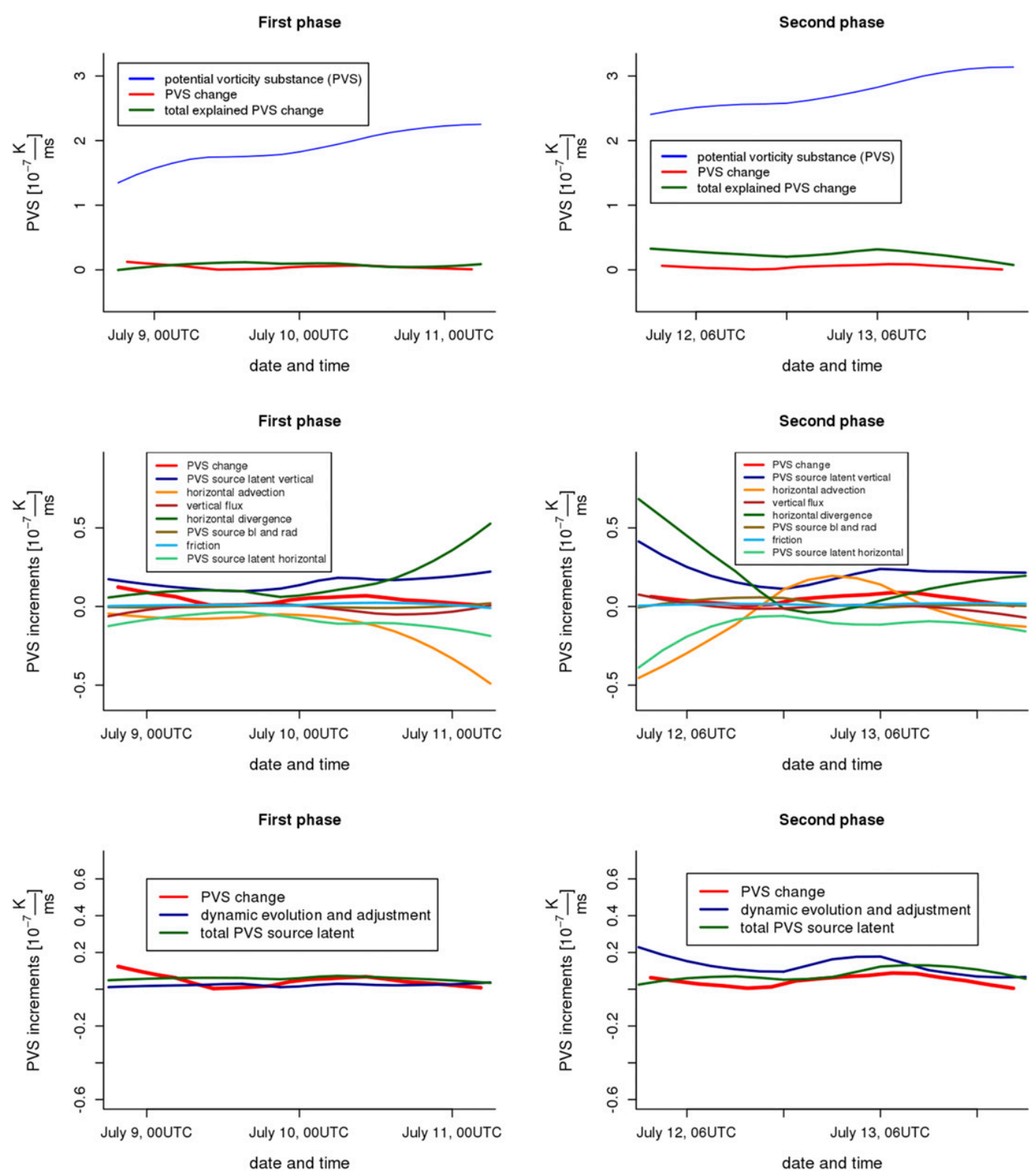

FIG. 11. Results of the PV budget analysis for the two periods of wave growth indicated by yellow shading in Fig. 1. (top) The blue lines show the evolution of the total PVS, the red lines show the time rate of change in PVS, and the green lines indicate the total change as calculated from the right-hand side of Eq. (2). (middle) The individual contributions from the terms introduced in Eqs. (3) and (4). (bottom) The red lines are again the total time rate of PVS change, the green lines are the sum of the horizontal and vertical PVS latent heat sources, and blue lines the sum of the horizontal advection and horizontal divergence terms.

the AEW system in the presence of organized convection (Haynes and McIntyre 1987; Tory et al. 2012).

\section{Mesoscale circulations and the role of the SAL}

In this section another aspect of the role of mesoscale circulations in AEWs is explored that relates to the organization of convection, the intensification of AEWs, and potentially their development into hurricanes over the tropical Atlantic. It involves the intrusion of air from the Saharan boundary layer into the AEW trough as the wave approaches the coast of West Africa. The SAL has previously been recognized as possibly important for the transition of cold-core AEWs into warm-core, rapidly rotating hurricanes, mainly from the perspective of radiative effects associated with dust transport into the 


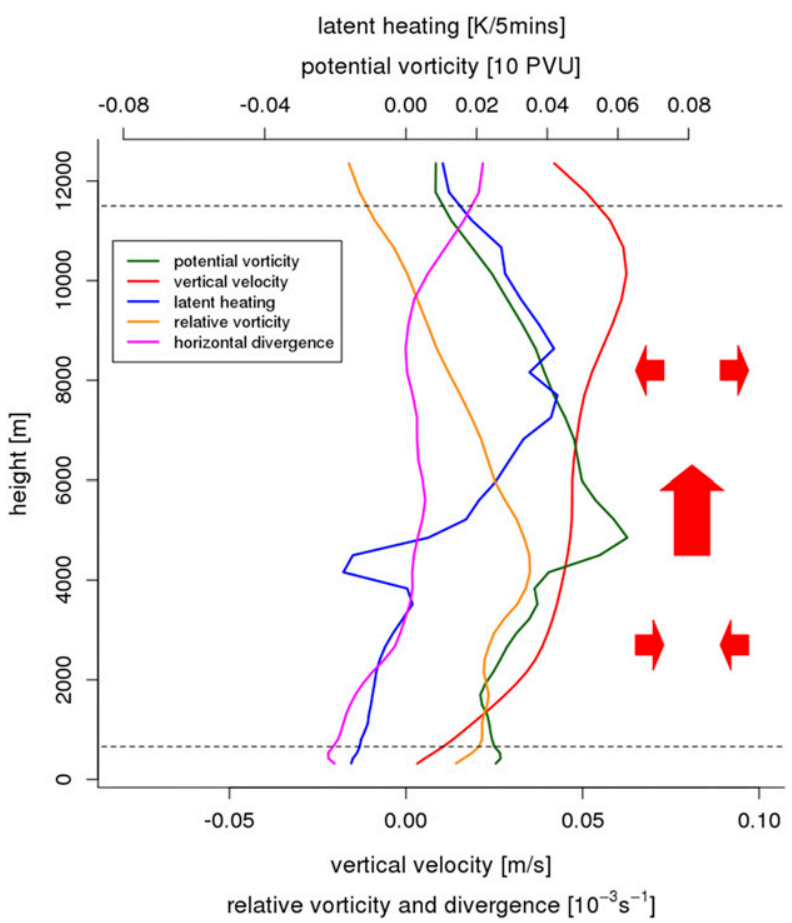

FIG. 12. Mean vertical structure of some of the quantities involved in the PV budget analysis at 0000 UTC 11 Jul. Dashed lines indicate the lower and upper boundaries of the box over which the PV budget is calculated. The red arrows indicate qualitatively the cycling of PVS with convergence at lower levels, upward transport, and divergence of PVS at upper levels of the troposphere.

AEW system (Jones et al. 2004) or microphysical impacts (Jenkins et al. 2008). But as Karyampudi and Carlson (1988) have pointed out, SAL intrusions may also reinforce AEWs dynamically by enhancing baroclinicity, meridional temperature gradients, and associated shear vorticity, and by rising motion near the SAL base caused by transverse-vertical circulations (see also Karyampudi et al. 1999; Karyampudi and Pierce 2002; Schwendike et al. 2016). Here we take a potential vorticity view and show that PV generated as a result of SAL intrusions can be a significant contribution to wave PV as the AEW passes from the West African coast across the Atlantic Ocean. Two mechanisms or pathways will be described by which the SAL may impact the PV budget of the wave.

For the analysis we use the PV tracer methodology applied in Tomassini et al. (2017). The definition of a PV tracer is briefly recapped here. The evolution equation for $\mathrm{PV}$ is

$$
\frac{D P}{D t}=\left(\frac{\zeta}{\rho}\right) \cdot \nabla S_{\theta}+\frac{\nabla \theta}{\rho} \cdot \nabla \times \mathbf{S}_{\mathbf{u}}
$$

where the notation is as in Eq. (3). The source terms $S_{\theta}$ and $\mathbf{S}_{\mathbf{u}}$ can be decomposed into a sum over different subgrid processes like convection, radiation, or boundary layer turbulent mixing. Thus Eq. (5) may formally be written as

$$
\frac{D P}{D t}=\sum_{\substack{\text { Parameterized } \\ \text { process } i}} d \mathrm{PVtrac}_{i} .
$$

Integrating both sides of the equation along a resolved flow trajectory $\mathbf{x}(t)$ of the model from start time $t_{\text {start }}$ to time $t$ gives

$$
\int_{t_{\text {start }}}^{t} \frac{D P}{D s} d s=\sum_{\begin{array}{c}
\text { Parameterized } \\
\text { process } i
\end{array}} \operatorname{PVtracer}_{i}(t)
$$

The individual PV tracer terms $\mathrm{PVtracer}_{i}$ are calculated along the model simulation and initialized with the value zero at the beginning of each forecast, hence their value depends on $t_{\text {start }}$.

The first mechanism through which the Saharan boundary layer may affect the PV evolution of the wave is related to the diurnal cycle of the boundary layer over the Sahara. During the day the Saharan boundary layer is well mixed by turbulence and dry convection through a depth of $3000 \mathrm{~m}$ and more (Fig. 13a). At the top of the SAL there is an inversion and a stable stratification above (Karyampudi and Carlson 1988; Karyampudi et al. 1999). In terms of PV this implies that positive PV can accumulate at and above the top of the Saharan boundary layer, especially at the southern edge of the SAL, where the wave contributes to forming a frontal zone with strong shear. In a way the existence of PV at the top of the Saharan boundary layer can be viewed as analogous to the accumulation of dust at the top of the daytime Saharan boundary layer (Karyampudi and Carlson 1988; Karyampudi et al. 1999). PV is produced near the surface after sunrise by dry convective mixing and then transported upward with the rising inversion at the top of the SAL during the afternoon.

Over the course of the night, the Saharan boundary layer collapses (Figs. 13c and 13e). The positive PV signature slides downward. The PV anomaly of the main wave center at around $12^{\circ} \mathrm{N}$ is connected to an area of positive PV that reaches into the Sahara (right panels of Fig. 13). Especially by 0600 UTC, when the turbulent mixing height has widely decreased to below $1000 \mathrm{~m}$, a trail of positive PV can be identified that feeds into the wave trough from the north at lower-tropospheric levels. Regions of the highest PV typically also exhibit a somewhat elevated turbulent mixing height, indicating the presence of strong shear. The formation of nocturnal jets over the Sahara, or a nighttime coastal jet reinforced 

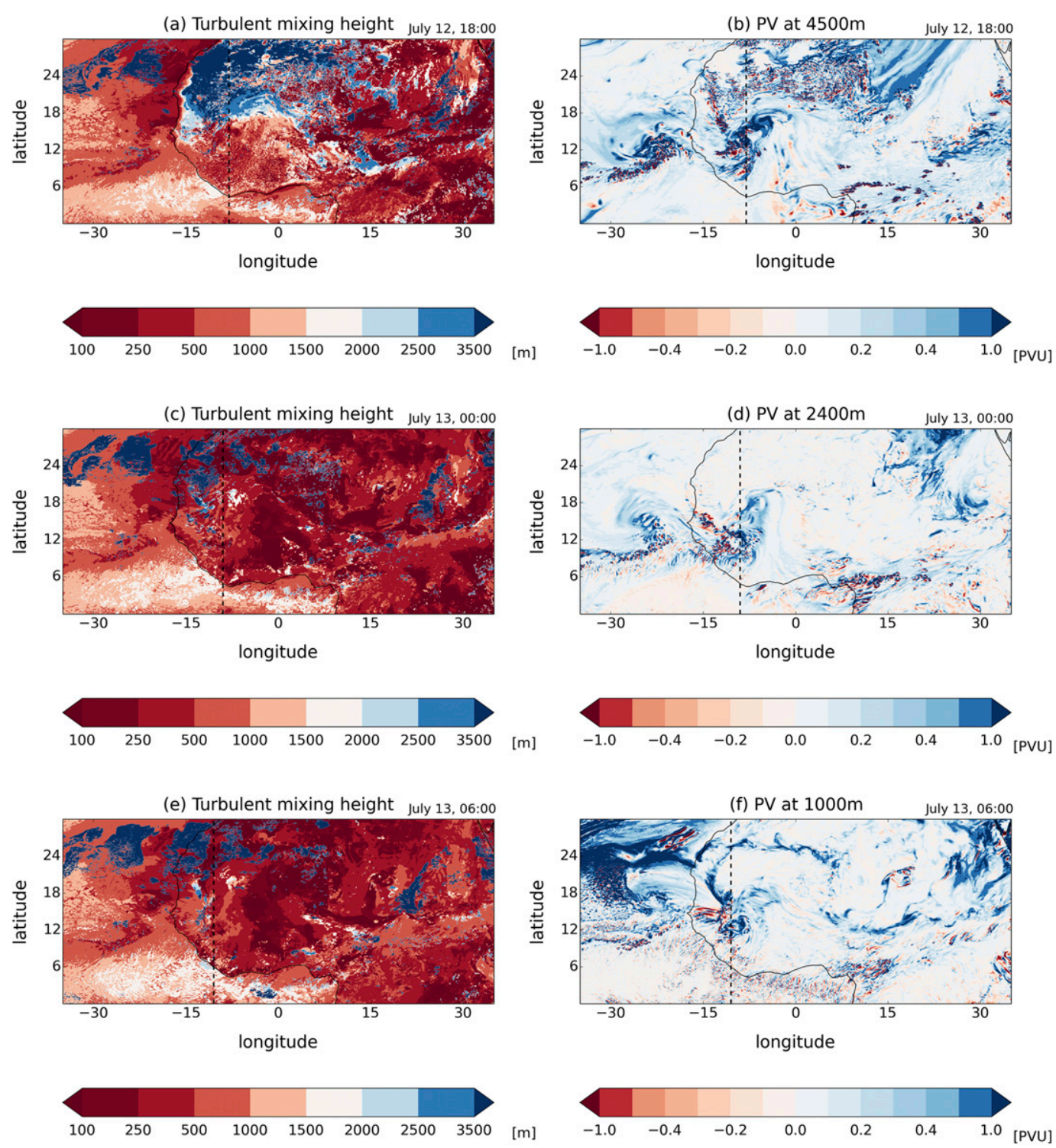

FIG. 13. Development of the (a),(c),(e) turbulent mixing height and (b),(d),(f) PV overnight. Three different times are shown: (top) 1800 UTC 12 Jul, (middle) 0000 UTC $13 \mathrm{Jul}$, and (bottom) 0600 UTC 13 Jul. PV is shown at different heights, corresponding to levels above the turbulent mixing height over the Sahara at the different points in time. Here the forecast with the 0000 UTC 11 Jul initial time is employed.

by the wave, helps to transport positive PV toward the wave trough (Westphal et al. 1988; Karyampudi et al. 1999).

The fact that positive PV anomalies are more pronounced at the edge of the AEW circulation is related to the second mechanism through which the Saharan boundary layer impacts the PV field, namely, baroclinic PV generation, as has been suggested by Karyampudi and Carlson (1988) (see also Karyampudi et al. 1999; Karyampudi and Pierce 2002). This mechanism is particularly relevant when the wave reaches the West African coast and starts to move across the Atlantic
Ocean. It is instructive to review the rather dramatic thermal structure of the atmosphere over the coastal area and the adjacent sea (Figs. 14a and 14b). At 1800 UTC 13 July, the wave trough has almost reached the coast (dashed lines in Fig. 14). At $1500 \mathrm{~m}$ above ground there is a very strong, fairly zonal temperature gradient from south to north. Over the Sahara the boundary layer is still deep and well mixed at 1800 UTC but not so near the coast and over the ocean. Isentropes connect low levels of the Saharan boundary layer with higher levels of the atmosphere near the coast and over 
(a) Theta at 1500 meter
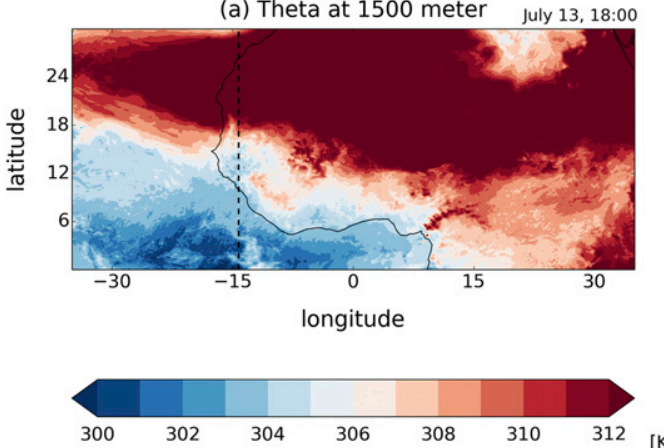

(c) Turbulent mixing height July 13, 18:00
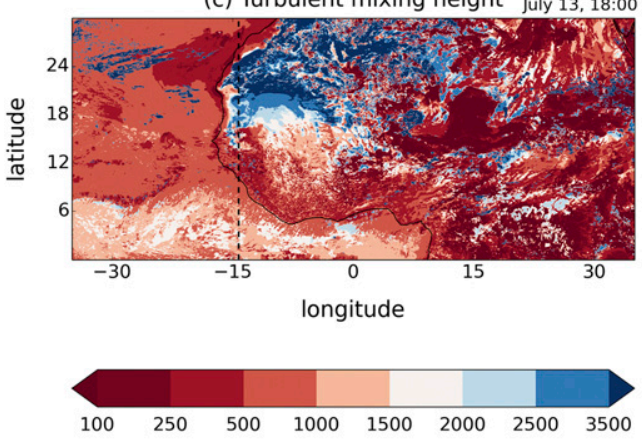

(e) Meridional wind at $850 \mathrm{hPa}$ July $13,18: 00$

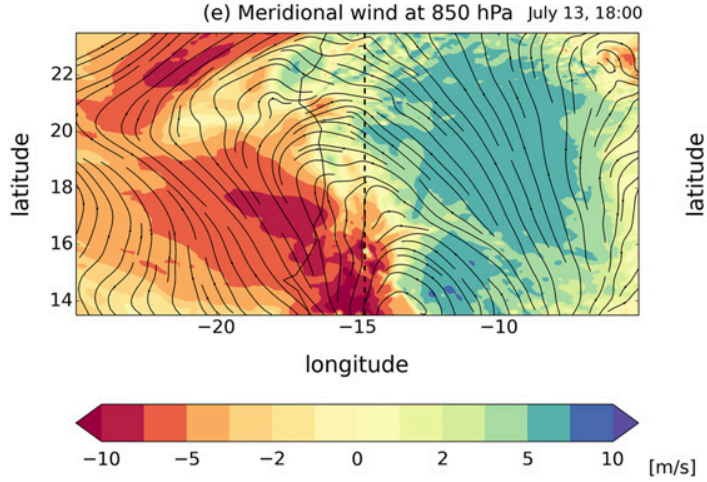

(b) Theta at 320 meter
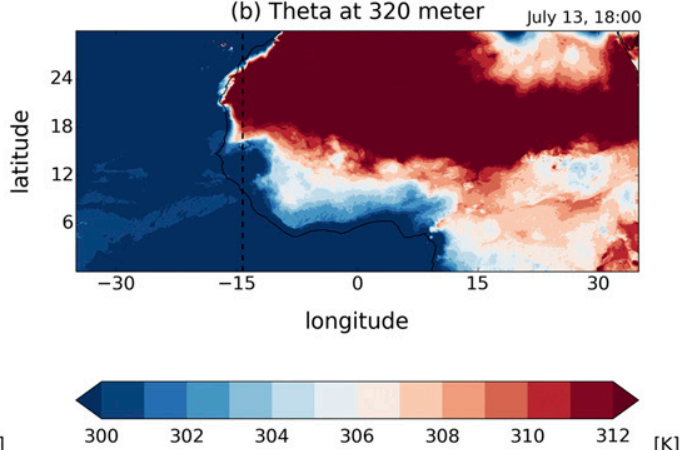

(d) BL shear-driven
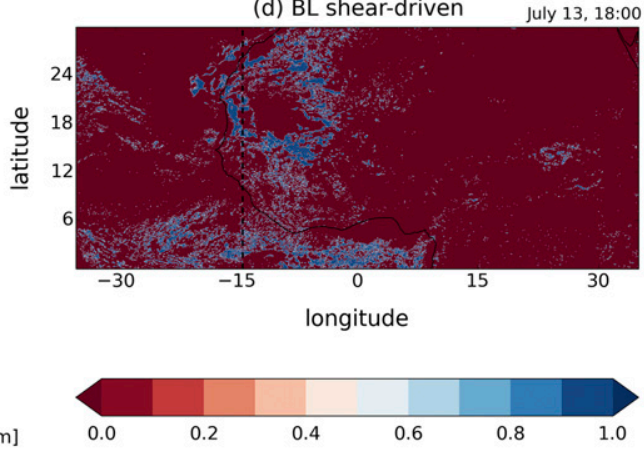

(f) Meridional wind at $700 \mathrm{hPa}$ July 13, 18:00

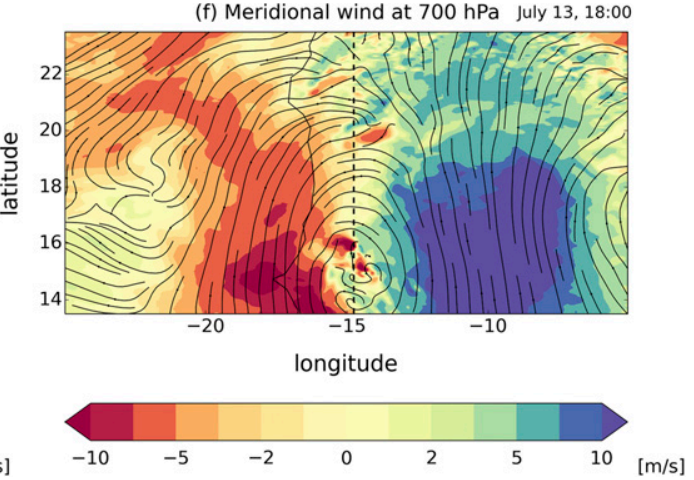

FIG. 14. Different quantities characterizing the meteorological conditions at 1800 UTC 13 Jul, when the wave trough approaches the coast of West Africa. Potential temperature at (a) 1500 and (b) $320 \mathrm{~m}$. (c) Turbulent mixing height and (d) boundary layer indicator for shear-driven boundary layers. A value of one in the indicator implies that the model diagnoses a shear-driven boundary layer. Wind anomalies for (e) 850 and (f) $700 \mathrm{hPa}$ (black streamlines); the color shading indicates meridional wind anomalies. The vertical dashed line represents the location of the wave trough.

the ocean. The southern edge of the SAL forms a sharp front. Over the ocean it rises toward the west above a moister and cooler layer of maritime air (Karyampudi and Carlson 1988; Karyampudi et al. 1999). Accordingly, the turbulent mixing height also shows a sharp drop close to the coast and on the southern boundary of the SAL (Fig. 14c). The model diagnoses a shear-driven boundary layer in the north just ahead of the wave trough (Fig. 14d). The area also corresponds to the edge of the Saharan boundary layer that is drawn southward by the wave circulation close to the coast. The wind anomaly at $850 \mathrm{hPa}$ induced by the passing AEW shows a tilted northwest-to-southeast circulation at 1800 UTC 13 July (Fig. 14e). This occurs because at this point in time the low-level northern vorticity center of the wave has partly merged with the main wave center farther south, resulting in the elongated and tilted structure of the wind anomaly at $850 \mathrm{hPa}$. The circulation anomaly implies that air is drawn in from the north along the coast, including SAL air that has already 
moved across the sea, toward the wave center farther south. The imprint of the main wave pattern can be best seen at the 700-hPa level (Fig. 14f). Rainfall at and ahead of the trough occurs only south of about $16^{\circ} \mathrm{N}$ (not shown). The baroclinic vertical tilt in the wave structure implied by the difference between the 850 - and $700-\mathrm{hPa}$ wind anomalies is also notable, mainly in the northern part of the wave (Tomassini et al. 2017). Detailed analyses of the airflow during the passage of AEWs across the West African coast have been described in separate cases by Karyampudi and Carlson (1988), Karyampudi et al. (1999), and Schwendike et al. (2016). The different cases, including the one discussed here, agree well in their characteristics, lending support to the suggestion that the situation examined in the present case study is typical.

Given the dramatic thermodynamic structure of the atmosphere over West Africa, it is appropriate to examine the PV dynamics on isentropic surfaces. To understand PV contributions from different processes, the PV tracer diagnostics will be used. To more clearly distinguish between the role of local processes and the advective source of PV, the following analysis will be based on a simulation with 1800 UTC 12 July as the forecast start time, and thus PV tracer initialization time. The left panels of Fig. 15 show the height of the chosen isentropic surfaces $24 \mathrm{~h}$ after initialization at $1800 \mathrm{UTC}$ 13 July. Areas where the potential temperature surface intersects with the lowest atmospheric model level are grayed out. There is a very narrow zone where the height of the isentropic surfaces rises abruptly from the ground to $600 \mathrm{~m}$ and more, implying dry convective and turbulent mixing. Along the coast, isentropic surfaces move upward markedly from north to south. To understand the atmospheric circulation, the right panels of Fig. 15 present the resolved wind on the same isentropic surfaces. From the absolute wind streamlines, it is obvious that at lower levels the circulation transports SAL air from the north toward the AEW center farther south. In the northwestern area of the depicted domain an anticyclonic circulation was established, in agreement with various other similar case studies that focused on the development of tropical cyclones, such as Karyampudi and Carlson (1988), Westphal et al. (1988), and Schwendike et al. (2016). This anticyclone supports the transport of SAL air toward more southern locations off the coast.

The PV distributions at 1800 UTC 13 July (left panels of Fig. 16) show positive PV along the coast of West Africa and over the ocean. The positive PV anomaly of the AEW can be identified mainly between $12^{\circ}$ and $16^{\circ} \mathrm{N}$, where most of the associated precipitation falls and latent heating occurs. The isentropic surfaces connect lower levels of the atmosphere at and in the vicinity of the coast with midtropospheric heights farther south at the location of the main wave trough. The circulation tends to transport positive $\mathrm{PV}$ from the north toward the wave center. The right panels of Fig. 16 show the resulting field when the initial PV at 1800 UTC 12 July, the time of the forecast initialization, is advected by the resolved flow over the course of $24 \mathrm{~h}$ without considering PV sources. The fact that there is a difference between the PV and the advected initial PV implies that some of the PV stems from locally generated PV produced over the course of the $24 \mathrm{~h}$.

Around the AEW center PV is generated mainly through latent heating (not shown). In the northern part of the domain and along the coast, PV is generated by low-level turbulent and convective mixing as can be seen from the PV tracers related to the subgrid boundary layer and convection parameterizations (Fig. 17). The PV contribution from the boundary layer scheme is located over land near the coast and in a region off the coast where the SAL glides over the shallow maritime boundary layer (left panels of Fig. 17). Subgrid convective mixing contributes to the positive PV pattern mainly at low levels over the ocean (right panels of Fig. 17). This evidence suggests that a baroclinic mechanism is at work, either through frictional generation (Adamson et al. 2006) or through transport and mixing of warm Saharan boundary layer air into the midtroposphere (Nakamura and Held 1989). The synoptic-scale deformation by the AEW draws air from the SAL toward the wave trough. The edges of the SAL air form areas that resemble a midlatitude front with strong convergence and wind shear (Karyampudi et al. 1999; Schwendike et al. 2016). Thus, the SAL intrusions result in zones of strong baroclinicity that reinforce the wave circulation. From an energetic perspective this corresponds to a conversion from zonal available potential energy to eddy available potential energy, and hence to eddy kinetic energy. In addition, Karyampudi and Carlson (1988) showed that at the southern SAL border, transversevertical circulations are induced that support the formation of lines of convection. These squall lines and the associated latent heating sustain the AEW through diabatic PV generation closer to the trough center. Karyampudi and Carlson (1988) confirmed through sensitivity experiments that the AEW growth is substantially weakened without the presence of the deep well-mixed daytime boundary layer over the Sahara and its influence on the wave development. Furthermore, Janiga and Thorncroft (2016) suggested that the intensification of the adiabatic forcing and changes in shear associated with the low-level northern vortex of 
(a) Height at $305 \mathrm{~K}$
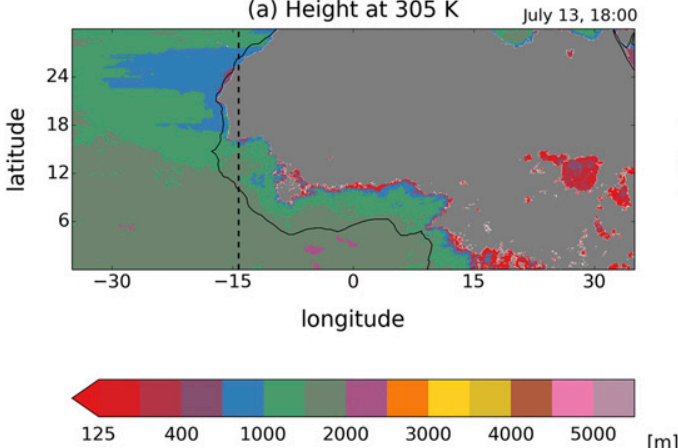

(c) Height at $310 \mathrm{~K}$
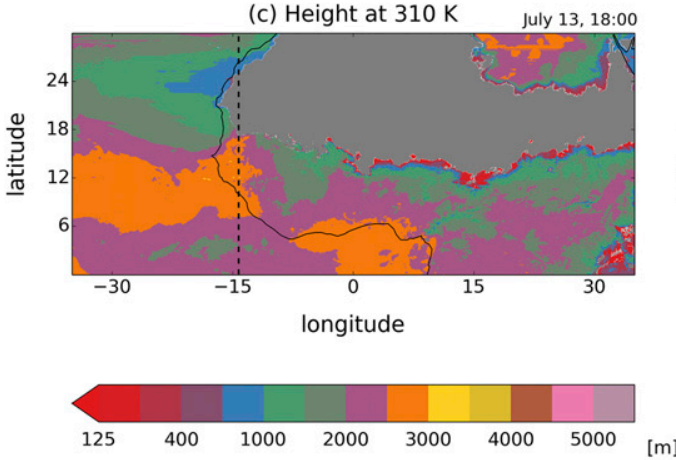

(b) Wind at $305 \mathrm{~K}$
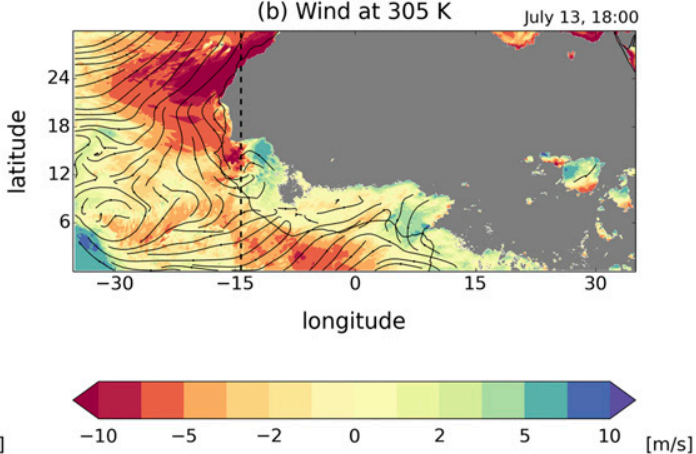

(d) Wind at $310 \mathrm{~K}$
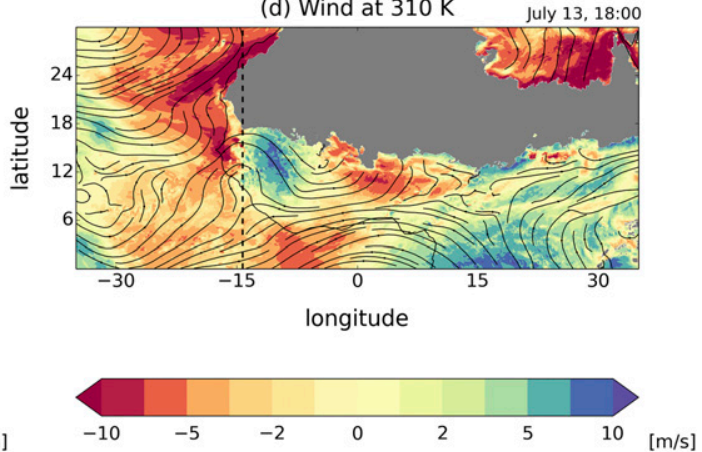

(e) Height at $315 \mathrm{~K}$
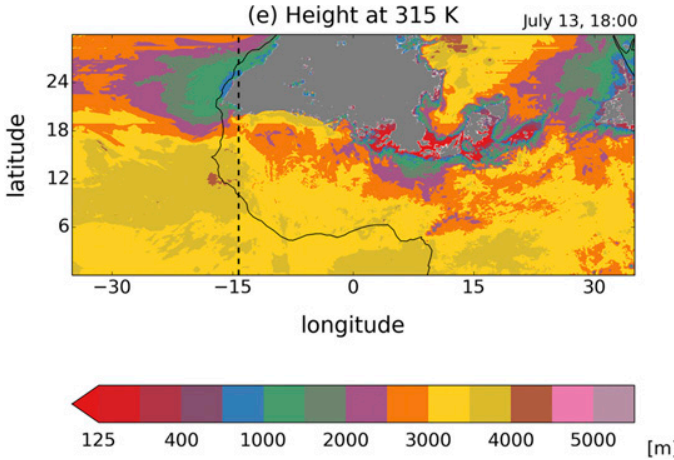

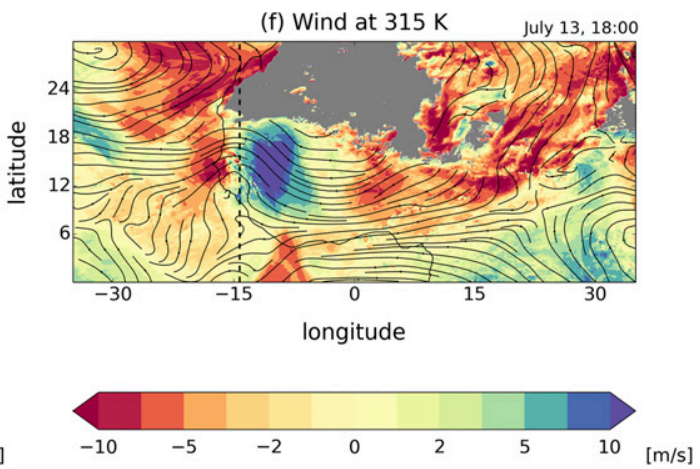

FIG. 15. The height of, and the wind field on, three different isentropic surfaces at 1800 UTC 13 Jul: (a),(b) 305; (c),(d) 310; and (e),(f) $315 \mathrm{~K}$. Color shading in (b), (d), and (f) represents the meridional component of the wind. The vertical dashed black line indicates the wave trough position. Areas where the potential temperature surfaces intersect with the lowest atmospheric model level are grayed out.

the wave contributes to the intensification of the convective activity and the wave amplitude farther south toward the coastal region and across the Atlantic. Consistent with this view, in the case investigated by Schwendike and Jones (2010), a low-level positive vorticity anomaly moved from the northern coastal region toward the southwest over the ocean and merged with the main $700-\mathrm{hPa}$ wave center before a tropical depression formed, which eventually transformed into a hurricane. A similar development can be seen in the present case (Fig. 18). In the late afternoon, positive relative vorticity along the coast ahead of the trough stretches from northern regions to farther south along the edge of the SAL. Over the course of $24 \mathrm{~h}$, it tends to be advected southward toward the wave trough and merges with the main $700-\mathrm{hPa}$ wave center.

In summary, the baroclinic mechanism of PV generation involving the SAL includes direct enhancement of baroclinicity and southward advection of relative vorticity, as well as indirect strengthening of organized convection and latent heat release through forced upward motions at the southern edge of the SAL (Karyampudi and Carlson 1988; Karyampudi and Pierce 2002). 

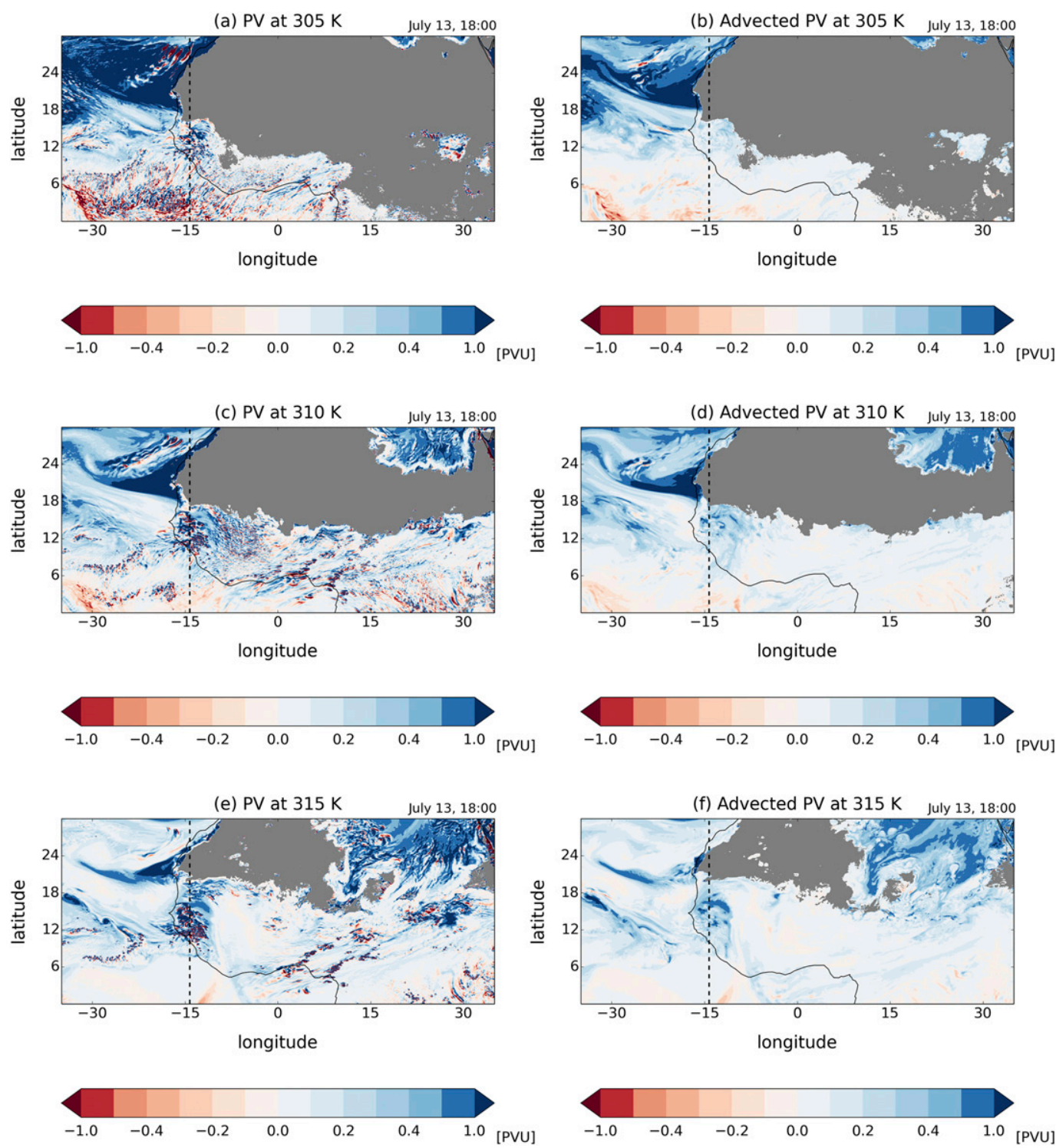

FIG. 16. (a),(c),(e) PV on three different isentropic surfaces: 305, 310, and $315 \mathrm{~K}$, respectively, at 1800 UTC 13 Jul. (b),(d),(f) PV distribution at 1800 UTC 13 Jul, resulting from the PV distribution of 1800 UTC 12 Jul being advected by the resolved flow, neglecting all PV sources during that 24-h period. Again, the same three isentropic surfaces are used, and areas where the potential temperature surfaces intersect with the lowest atmospheric model level are grayed out.

\section{Summary and conclusions}

In this study global convection-permitting simulations of a strong AEW are investigated in order to shed light on the two-way interaction between the atmospheric circulation on various scales and organized convection. The structure of a mesoscale convective system ahead of the wave trough, the mechanisms that sustain the MCS, and its relation to the synoptic-scale wave are examined. The MCS develops a strong and distinct frontal line of upward vertical velocities, with a stratiform cloud and rainfall region behind. This front collides with the low-level southwesterly monsoon flow that feeds high-moist-static-energy air into the system. The main inflow direction into the MCS, however, is from the northeast - that is, from behind-partly because of its own sustaining mesoscale circulation and partly because of the synoptic-scale wave dynamics. This main inflow comes with a positive moisture anomaly and supports the propagation of the system westward. In addition, related lower-tropospheric moisture convergence and shear also precondition and organize convection ahead of the wave trough and the MCS front, not unlike in extratropical situations (e.g., Hanley et al. 2013). A key 
(a) PV boundary layer at $305 \mathrm{~K}$ july 13, 18:00
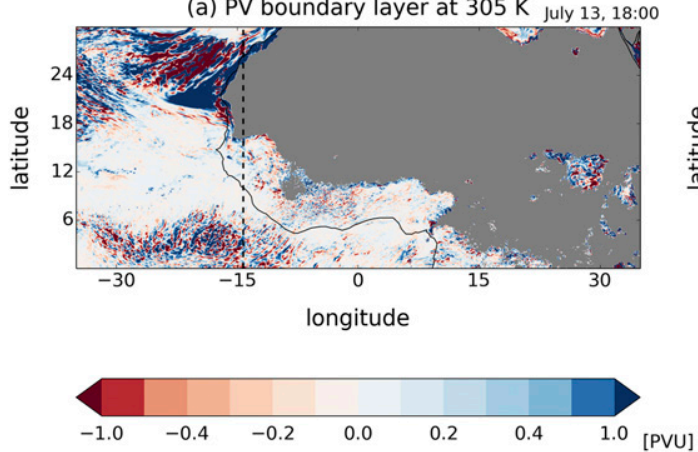

(c) PV boundary layer at $310 \mathrm{~K}$ July 13, 18:00
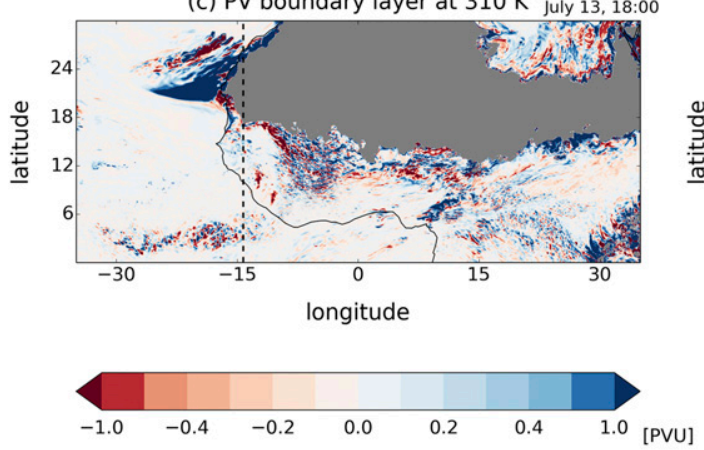

(e) PV boundary layer at $315 \mathrm{~K}$ july $13,18: 00$
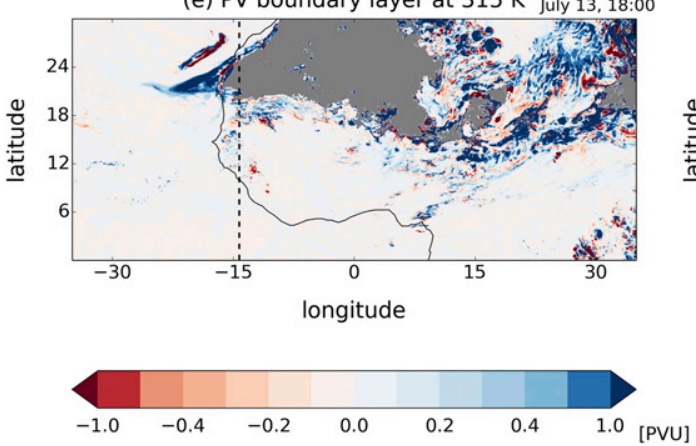

(b) PV convection at $305 \mathrm{~K}$ july 13, 18:00
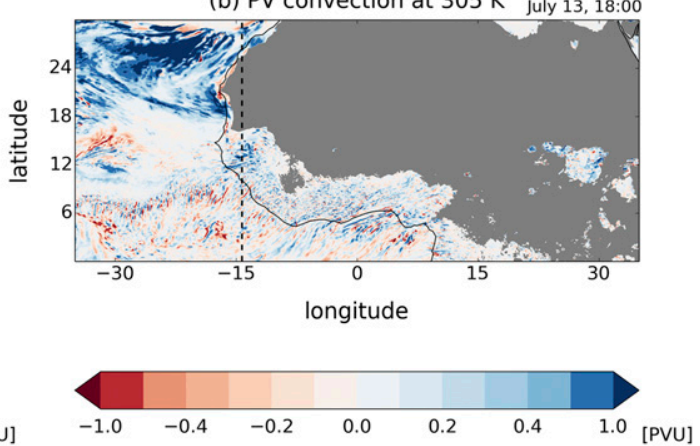

(d) PV convection at $310 \mathrm{~K}$ july $13,18: 00$
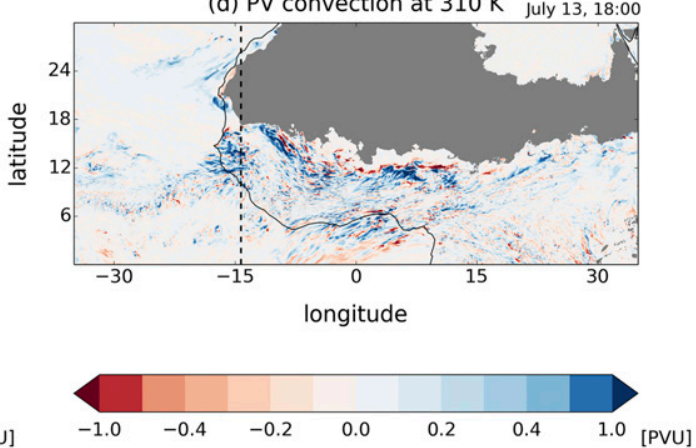

(f) PV convection at $315 \mathrm{~K}$ July 13, 18:00
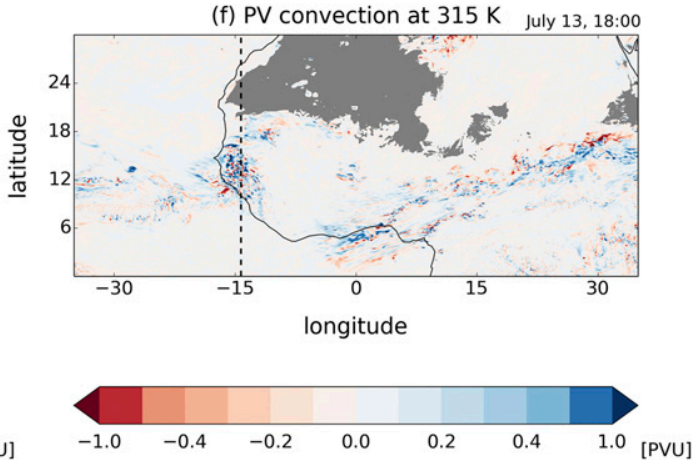

FIG. 17. The PV tracer associated with (a),(c),(e) the subgrid boundary layer parameterization and (b),(d),(f) the subgrid convection parameterization on three different isentropic surfaces at 1800 UTC 13 July: (top) 305, (middle) 310, and (bottom) $315 \mathrm{~K}$. The vertical dashed black line indicates the wave trough position. Areas where the potential temperature surfaces intersect with the lowest atmospheric model level are grayed out.

characteristic of the system is a shell of moisture around the convective core region, a feature that has an impact on entrainment dynamics (Becker et al. 2018). Thus, in the investigated case mesoscale downdrafts may contribute to sustaining the MCS but are not the main mechanism as suggested in other studies of squall clusters (e.g., Houze 1977). Cloud-top cooling plays a negligible role in maintaining the MCS through the night. The model likely overestimates the degree of convective organization, and satellite scenes suggest that there are often two or more convective fronts present around the wave trough. Nevertheless, the indications are that qualitatively the simulation correctly reproduces the processes that sustain the MCS.

Thus, in the examined situation larger-scale forcing through moisture convergence in the lower midtroposphere is an important aspect in the development of organized convection (Hohenegger and Stevens 2013). Crucially, the interaction between the larger scale and the convective scale is mediated by mesoscale circulations, both upscale and downscale. In the downscale direction, the mesoscale circulations associated with the MCS are supported and partly induced by the synopticscale wave circulation, and are key in triggering and 
(a) Relative vorticity at $310 \mathrm{~K}$ july $13,18: 00$
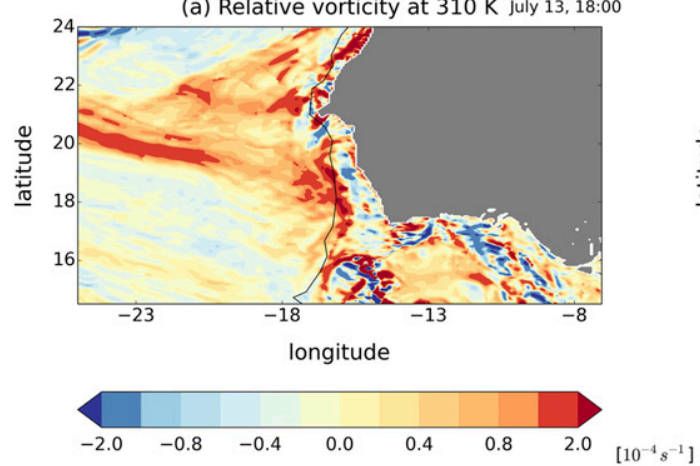

(c) Relative vorticity at $310 \mathrm{~K}$ July $14,06: 00$

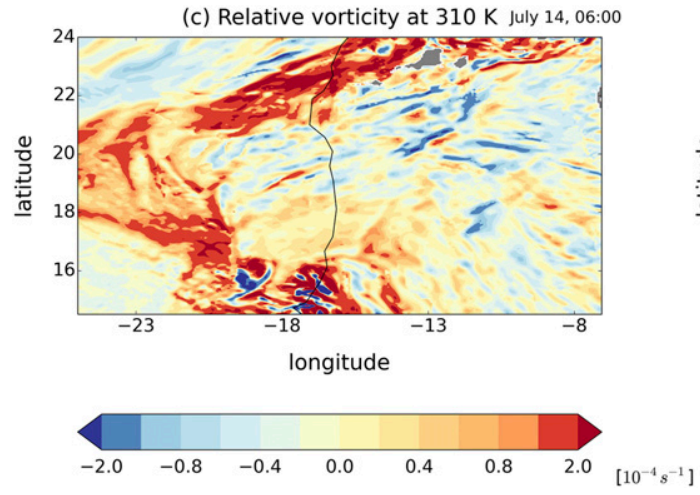

(b) Relative vorticity at $310 \mathrm{~K}$ July $14,00: 00$
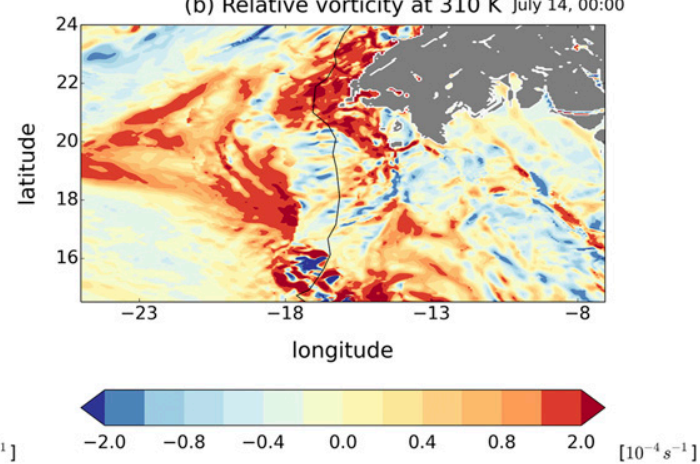

(d) Relative vorticity at $310 \mathrm{~K}$ July $14,18: 00$
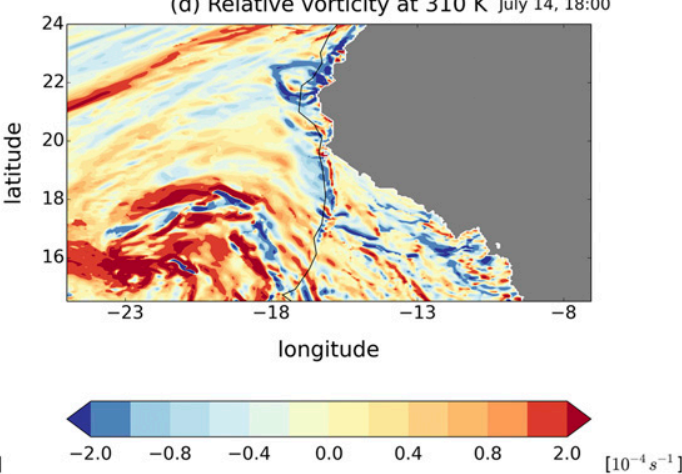

FIG. 18. Evolution of the relative vorticity on the 310-K potential temperature surface for four different times between (a) 1800 UTC $13 \mathrm{Jul}$ and (d) 1800 UTC 14 Jul. The dashed line in (a) indicates the trough location at 1800 UTC 13 Jul. Areas where the isentropic surface intersects with the lowest atmospheric model level are grayed out.

establishing a self-sustaining MCS. In the upscale direction, convective latent heating drives mesoscale circulations that feed into the wave dynamics via PV generation and reinforce the AEW.

That diabatic processes are an important contribution to wave PV is demonstrated in more detail in a PV budget analysis. The decomposition of the temporal PV tendency demonstrates that although dynamic and advective processes can play an important role in the PV evolution of the wave, they are not independent of the PV created by latent heating, and diabatic latent heating is a driving force of wave growth. Indeed, during certain stages of the AEW evolution, the balanced dynamics of the wave becomes dominated by convective heating (Parker and Thorpe 1995). But the analysis also clearly shows that the wave propagation is not a quasi-static process. Rather, the wave can be viewed as a "breathing creature" that is characterized by a succession of convective bursts and subsequent dynamic adjustment processes.

It has been previously observed that convective bursts and mesoscale circulations embedded in AEWs are essential in the development of AEWs into tropical cyclones (Gray 1998). Karyampudi and Carlson (1988) suggested that the presence of the Saharan boundary layer contributes to intensifying AEWs and may be an important factor in the transition of AEWs into tropical depressions and hurricanes. More recently, an analysis of the genesis of MCSs over the West African Sahel by Vizy and Cook (2018) highlighted the crucial role of the Sahel intertropical front and associated wind convergence resulting from dryline dynamics. Therefore, the role of SAL intrusions into the wave trough is investigated in some detail mainly from a PV perspective. Two pathways are described through which positive PV anomalies can be generated in the southern Sahara and northern Sahel and transported toward the wave trough. First, the generation of a deep well-mixed daytime boundary layer over the Sahara can lead to an establishment of positive PV anomalies at and above the top of the Saharan boundary layer. During the night the height of the Saharan boundary layer collapses and PV may be transported toward the AEW trough at lower levels farther south. Nocturnal jets over the Sahara or a coastal jet can contribute to advecting PV southward. Second, a baroclinic mechanism involving SAL air can generate positive $\mathrm{PV}$ anomalies mainly at the southern and frontal edges of the SAL. These fronts are impacted by the passage of the wave, and mesoscale circulations can lead to 
SAL air intrusions into the wave trough. The baroclinic mechanism involves wave intensification through local increases of baroclinicity and wind shear, and reinforcement of convective organization and latent heat release by transverse-vertical circulations induced by SAL excursions. The existence of dry convective and turbulent uplift within the SAL is consistent with the fact that the observed long-range retention and transport of coarse mode dust particles across the eastern Atlantic cannot be explained solely by assuming gravitational sedimentation (Ryder et al. 2013). Advection of low-level relative vorticity southward and a merging of the main $\mathrm{AEW}$ center with this low-level northern vorticity may also be part of the mechanism and induce reinforcement of the AEW.

In a more general context, the present work highlights the important role of a lower- and midtropospheric control of organized convection through moisture dynamics (Raymond and Herman 2011; Schiro et al. 2016), and emphasizes the fact that there is no scale separation between balanced dynamics and smaller-scale convection. Synopticscale disturbances like AEWs are interlinked with organized convection through mesoscale circulations on a range of scales. This is true in both ways, upscale and downscale. The wave growth can be dominated by convective heating that leads to PV being fed into the wave through various intermediate-scale motions. Moist convection in turn is governed and organized by mesoscale circulations initiated by the wave disturbance. This implies that there is an intimate and intrinsically dynamic relation between moist convection and the atmospheric circulation, a reason why subgrid convection parameterizations in numerical models struggle to represent this interaction adequately.

Acknowledgments. Help with the computation of the MSG simulated images by Thomas Blackmore is gratefully acknowledged. The author would like to thank Douglas J. Parker, Andrew Bushell, Paul Earnshaw, Malcolm Brooks, and Martin Willett for the useful discussions and advice. This study was supported by the Natural Environment Research Council/Department for International Development via the Future Climate for Africa (FCFA)funded project Improving Model Processes for African Climate (IMPALA; NE/M017265/1).

\section{REFERENCES}

Adamson, D. S., S. E. Belcher, B. J. Hoskins, and R. S. Plant, 2006: Boundary-layer friction in midlatitude cyclones. Quart. J. Roy. Meteor. Soc., 132, 101-124, https://doi.org/10.1256/qj.04.145.

Arakawa, A., and W. H. Schubert, 1974: Interaction of a cumulus cloud ensemble with the large-scale environment, Part I. J. Atmos. Sci., 31, 674-701, https://doi.org/10.1175/1520-0469(1974)031<0674: IOACCE $>2.0 . C O ; 2$.
Becker, T., C. S. Bretherton, C. Hohenegger, and B. Stevens, 2018: Estimating bulk entrainment with unaggregated and aggregated convection. Geophys. Res. Lett., 45, 455-462, https://doi.org/ 10.1002/2017GL076640.

Berry, G. J., and C. D. Thorncroft, 2005: Case study of an intense African easterly wave. Mon. Wea. Rev., 133, 752-766, https:// doi.org/10.1175/MWR2884.1.

—_, and - - 2012: African easterly wave dynamics in a mesoscale numerical model: The upscale role of convection. J. Atmos. Sci., 69, 1267-1283, https://doi.org/10.1175/JAS-D11-099.1.

Bretherton, C. S., and P. N. Blossey, 2017: Understanding mesoscale aggregation of shallow cumulus convection using largeeddy simulation. J. Adv. Model. Earth Syst., 9, 2798-2821, https://doi.org/10.1002/2017MS000981.

Burpee, R. W., 1975: Some features of synoptic-scale waves based on a compositing analysis of GATE data. Mon. Wea. Rev., 103, 921-925, https://doi.org/10.1175/1520-0493(1975)103<0921: SFOSWB $>2.0 . \mathrm{CO} ; 2$.

Charney, J. G., 1963: A note on the large-scale motions in the tropics. J. Atmos. Sci., 20, 607-609, https://doi.org/10.1175/ 1520-0469(1963)020<0607:ANOLSM > 2.0.CO;2.

_- , and A. Eliassen, 1964: On the growth of the hurricane depression. J. Atmos. Sci., 21, 68-75, https://doi.org/10.1175/ 1520-0469(1964)021<0068:OTGOTH > 2.0.CO;2.

Davies, H. C., 1979: Phase-lagged wave-CISK. Quart. J. Roy. Meteor. Soc., 105, 325-353, https://doi.org/10.1002/qj.49710544402.

Dunn, G. E., 1940: Cyclogenesis in the tropical Atlantic. Bull. Amer. Meteor. Soc., 21, 215-229, https://doi.org/10.1175/15200477-21.6.215.

Emanuel, K. A., J. D. Neelin, and C. S. Bretherton, 1994: On large-scale circulations in convective atmospheres. Quart. J. Roy. Meteor. Soc., 120, 1111-1143, https://doi.org/10.1002/ qj. 49712051902.

Gray, W. M., 1998: The formation of tropical cyclones. Meteor. Atmos. Phys., 67, 37-69, https://doi.org/10.1007/BF01277501.

Guilloteau, C., R. Roca, and M. Gosset, 2016: A multiscale evaluation of the detection capabilities of high-resolution satellite precipitation products in West Africa. J. Hydrometeor., 17, 2041-2059, https://doi.org/10.1175/JHM-D-15-0148.1.

Hanley, K. E., D. J. Kirshbaum, N. M. Roberts, and G. Leoncini, 2013: Sensitivities of a squall line over central Europe in a convective-scale ensemble. Mon. Wea. Rev., 141, 112-133, https://doi.org/10.1175/MWR-D-12-00013.1.

Haynes, P. H., and M. E. McIntyre, 1987: On the evolution of vorticity and potential vorticity in the presence of diabatic heating and frictional and other forces. J. Atmos. Sci., 44, 828-841, https://doi.org/10.1175/1520-0469(1987)044<0828: OTEOVA $>2.0 . \mathrm{CO} ; 2$.

Hoerling, M. P., 1992: Diabatic sources of potential vorticity in the general circulation. J. Atmos. Sci., 49, 2282-2292, https:// doi.org/10.1175/1520-0469(1992)049<2282:DSOPVI>2.0.CO;2.

Hohenegger, C., and B. Stevens, 2013: Preconditioning deep convection with cumulus congestus. J. Atmos. Sci., 70, 448-464, https://doi.org/10.1175/JAS-D-12-089.1.

Holloway, C. E., and J. D. Neelin, 2007: The convective cold top and quasi equilibrium. J. Atmos. Sci., 64, 1467-1487, https:// doi.org/10.1175/JAS3907.1.

Houze, R. A., 1977: Structure and dynamics of a tropical squall-line system. Mon. Wea. Rev., 105,1540-1567, https://doi.org/10.1175/ 1520-0493(1977)105<1540:SADOAT >2.0.CO;2.

_, and A. K. Betts, 1981: Convection in GATE. Rev. Geophys., 19, 541-576, https://doi.org/10.1029/RG019i004p00541. 
Huffman, G. J., and Coauthors, 2007: The TRMM Multisatellite Precipitation Analysis: Quasi-global, multiyear, combinedsensor precipitation estimates at fine scale. J. Hydrometeor., 8, 38-55, https://doi.org/10.1175/JHM560.1.

Janiga, M. A., and C. D. Thorncroft, 2016: The influence of African easterly waves on convection over tropical Africa and the east Atlantic. Mon. Wea. Rev., 144, 171-192, https://doi.org/10.1175/ MWR-D-14-00419.1.

Jenkins, G. S., A. S. Pratt, and A. Heymsfield, 2008: Possible linkages between Saharan dust and tropical cyclone rain band invigoration in the eastern Atlantic during NAMMA-06. Geophys. Res. Lett., 35, L08815, https://doi.org/10.1029/ 2008 GL034072.

— tures in Senegal during the African Monsoon Multidisciplinary Analysis Special Observing Period 3.J. Geophys. Res., 115, D18108, https://doi.org/10.1029/2009JD013022.

Jones, C., N. Mahowald, and C. Luo, 2004: Observational evidence of African desert dust intensification of easterly waves. Geophys. Res. Lett., 31, L17208, https://doi.org/10.1029/ 2004GL020107.

Karyampudi, V. M., and T. Carlson, 1988: Analysis and numerical simulations of the Saharan Air Layer and its effects on easterly wave disturbances. J. Atmos. Sci., 45, 3102-3136, https://doi.org/ 10.1175/1520-0469(1988)045<3102:AANSOT>2.0.CO;2.

—_, and H. F. Pierce, 2002: Synoptic-scale influence of the Saharan air layer on tropical cyclogenesis over the eastern Atlantic. Mon. Wea. Rev., 130, 3100-3128, https://doi.org/ 10.1175/1520-0493(2002)130<3100:SSIOTS > 2.0.CO;2.

— conceptual model using lidar, Meteosat, and ECMWF data. Bull. Amer. Meteor. Soc., 80, 1045-1075, https://doi.org/ 10.1175/1520-0477(1999)080<1045:VOTSDP > 2.0.CO;2.

Lafore, J.-P., and Coauthors, 2017: A multi-scale analysis of the extreme rain event of Ouagadougou in 2009. Quart. J. Roy. Meteor. Soc., 143, 3094-3109, https://doi.org/10.1002/qj.3165.

Lewis, J. M., M. G. Fearon, and H. E. Klieforth, 2012: Herbert Riehl: Intrepid and enigmatic scholar. Bull. Amer. Meteor. Soc., 93, 963-985, https://doi.org/10.1175/BAMS-D-1100224.1 .

Nakamura, N., and I. M. Held, 1989: Nonlinear equilibration of two-dimensional Eady waves. J. Atmos. Sci., 46, 3055-3064, https://doi.org/10.1175/1520-0469(1989)046<3055:NEOTDE > 2.0.CO;2.

Neelin, J. D., and I. M. Held, 1987: Modeling tropical convergence based on the moist static energy budget. Mon. Wea. Rev., 115, 3-12, https://doi.org/10.1175/1520-0493(1987)115<0003: $\mathrm{MTCBOT}>2.0 . \mathrm{CO} ; 2$.

Parker, D. J., and A. J. Thorpe, 1995: Conditional convective heating in a baroclinic atmosphere: A model of convective frontogenesis. J. Atmos. Sci., 52, 1699-1711, https://doi.org/ 10.1175/1520-0469(1995)052<1699:CCHIAB > 2.0.CO;2.

Pfeifroth, U., and J. Trentmann, 2016: Evaluating satellite-based diurnal cycles of precipitation in the African tropics. J. Appl. Meteor. Climatol., 55, 23-39, https://doi.org/10.1175/JAMC-D15-0065.1.

Raymond, D. J., and M. J. Herman, 2011: Convective quasiequilibrium reconsidered. J. Adv. Model. Earth Syst., 3, M08003, https://doi.org/10.1029/2011MS000079.

, Z. Fuchs, S. Gjorgjievska, and S. Sessions, 2015: Balanced dynamics and convection in the tropical troposphere. J. Adv. Model. Earth Syst., 7, 1093-1116, https://doi.org/ 10.1002/2015MS000467.
Reed, R. J., D. C. Norquist, and E. E. Recker, 1977: The structure and properties of African wave disturbances as observed during phase III of GATE. Mon. Wea. Rev., 105, 317-333, https://doi.org/10.1175/1520-0493(1977)105<0317:TSAPOA > 2.0.CO;2.

Riehl, H., 1945: Waves in the easterlies and the polar front in the tropics. University of Chicago Miscellaneous Rep. 17, $79 \mathrm{pp}$.

—, 1954: Tropical Meteorology. Wiley-Blackwell, 392 pp.

Ryder, C. L., E. J. Highwood, T. M. Lai, H. Sodemann, and J. H. Marsham, 2013: Impact of atmospheric transport on the evolution of microphysical and optical properties of Saharan dust. Geophys. Res. Lett., 40, 2433-2438, https://doi.org/10.1002/ grl.50482.

Schiro, K. A., J. D. Neelin, D. K. Adams, and B. R. Lintner, 2016: Deep convection and column water vapor over tropical land versus tropical ocean: A comparison between the Amazon and the tropical western Pacific. J. Atmos. Sci., 73, 4043-3064, https://doi.org/10.1175/JAS-D-16-0119.1.

Schulz, H., and B. Stevens, 2018: Observing the tropical atmosphere in moisture space. J. Atmos. Sci., 75, 3313-3330, https:// doi.org/10.1175/JAS-D-17-0375.1.

Schwendike, J., and S. C. Jones, 2010: Convection in an African Easterly Wave over West Africa and the eastern Atlantic: A model case study of Helene (2006). Quart. J. Roy. Meteor. Soc., 136, 364-396, https://doi.org/10.1002/qj.566.

,-- , B. Vogel, and H. Vogel, 2016: Mineral dust transport toward hurricane Helene (2006). J. Geophys. Res. Atmos., 121, 5538-5566, https://doi.org/10.1002/2015JD024708.

Seitter, K. L., and H.-L. Kuo, 1983: The dynamical structure of squall-line type thunderstorms. J. Atmos. Sci., 40, 2831-2854, https://doi.org/10.1175/1520-0469(1983)040<2831:TDSOSL $>$ 2.0.CO;2.

Siongco, A. C., C. Hohenegger, and B. Stevens, 2017: Sensitivity of the summertime tropical Atlantic precipitation distribution to convective parameterization and model resolution in ECHAM6. J. Geophys. Res. Atmos., 122, 2579-2594, https:// doi.org/10.1002/2016JD026093.

Skinner, C. B., and N. S. Diffenbaugh, 2013: The contribution of African easterly waves to monsoon precipitation in the CMIP3 ensemble. J. Geophys. Res. Atmos., 118, 3590-3609, https:// doi.org/10.1002/jgrd.50363.

Smith, R. K., 1997: On the theory of CISK. Quart. J. Roy. Meteor. Soc., 123, 407-418, https://doi.org/10.1002/qj.49712353808.

Thompson, R. M., S. W. Payne, E. E. Recker, and R. J. Reed, 1979: Structure and properties of synoptic-scale wave disturbances in the Intertropical Convergence Zone of the eastern Atlantic. J. Atmos. Sci., 36, 53-72, https://doi.org/10.1175/1520-0469(1979) 036<0053:SAPOSS $>2.0$.CO;2.

Tomassini, L., D. J. Parker, A. Stirling, C. Bain, C. Senior, and S. Milton, 2017: The interaction between moist diabatic processes and the atmospheric circulation in African Easterly Wave propagation. Quart. J. Roy. Meteor. Soc., 143, 32073227, https://doi.org/10.1002/qj.3173.

Tory, K. J., M. T. Montgomery, N. E. Davidson, and J. D. Kepert, 2006: Prediction and diagnosis of tropical cyclone formation in an NWP system. Part II: A diagnosis of tropical cyclone Chris formation. J. Atmos. Sci., 63, 3091-3113, https://doi.org/10.1175/ JAS3765.1.

, J. D. Kepert, J. A. Sippel, and C. M. Nguyen, 2012: On the use of potential vorticity tendency equations for diagnosing atmospheric dynamics in numerical models. J. Atmos. Sci., 69 , 942-960, https://doi.org/10.1175/JAS-D-10-05005.1. 
Uccellini, L. W., and P. J. Kocin, 1987: The interaction of jet streak circulations during heavy snow events along the East Coast of the United States. Wea. Forecasting, 2, 289-308, https://doi.org/ 10.1175/1520-0434(1987)002<0289:TIOJSC $>2.0 . C O ; 2$.

Vizy, E. K., and K. H. Cook, 2018: Mesoscale convective systems and nocturnal rainfall over the West African Sahel: Role of the Inter-tropical front. Climate Dyn., 50, 587-614, https://doi.org/ 10.1007/s00382-017-3628-7.

Walters, D., and Coauthors, 2017: The Met Office Unified Model Global Atmosphere 7.0/7.1 and JULES Global Land 7.0 configurations. Geosci. Model Dev. Discuss., https://doi.org/ 10.5194/gmd-2017-291.

Westphal, D. L., O. B. Toon, and T. N. Carlson, 1988: A case study of mobilization and transport of Saharan dust. J. Atmos. Sci., 45, 2145-2175, https://doi.org/10.1175/15200469(1988)045<2145:ACSOMA>2.0.CO;2.

$\mathrm{Xu}, \mathrm{K}$., and K. A. Emanuel, 1989: Is the tropical atmosphere conditionally unstable? Mon. Wea. Rev., 117, 1471-1479, https://doi.org/10.1175/1520-0493(1989)117<1471:ITTACU> 2.0.CO;2. 